University of South Carolina

Scholar Commons

$5-1993$

\title{
Scaling Water and Energy Fluxes in Climate Systems: Three Land- Atmospheric Modeling Experiments
}

\author{
Eric F. Wood \\ Venkataraman Lakshmi \\ University of South Carolina - Columbia, vlakshmi@geol.sc.edu
}

Follow this and additional works at: https://scholarcommons.sc.edu/geol_facpub

Part of the Earth Sciences Commons

Publication Info

Published in Journal of Climate, Volume 6, Issue 5, 1993, pages 839-857.

Wood, E. F. \& Lakshmi, V. (1993). Scaling water and energy fluxes in climate systems: three landatmospheric modeling experiments. Journal of Climate, 6 (5), 839-857.

(c) Copyright 1993 AMS

This Article is brought to you by the Earth, Ocean and Environment, School of the at Scholar Commons. It has been accepted for inclusion in Faculty Publications by an authorized administrator of Scholar Commons. For more information, please contact digres@mailbox.sc.edu. 


\title{
Scaling Water and Energy Fluxes in Climate Systems: Three Land-Atmospheric Modeling Experiments
}

\author{
ERIC F. WOOD AND VENKATARAMAN LAKSHMI \\ Water Resources Program, Princeton University, Princeton, New Jersey
}

(Manuscript received on 25 October 1991, in final form 15 June 1992)

\begin{abstract}
The effects of small-scale heterogeneity in land-surface characteristics on the large-scale fluxes of water and energy in the land-atmosphere system have become a central focus of many of the climatology research experiments. The acquisition of high-resolution land-surface data through remote sensing and intensive landclimatology field experiments (like HAPEX and FIFE) has provided data to investigate the interactions between microscale land-atmosphere interactions and macroscale models. One essential research question is how to account for the small-scale heterogeneities and whether "effective" parameters can be used in the macroscale models. To address this question of scaling, three modeling experiments were performed and are reviewed in the paper. The first is concerned with the land-surface hydrology during rain events and between rain events. The second experiment applies the Simple Biosphere Model ( $\mathrm{SiB})$ to a heterogeneous domain and the spatial and temporal latent heat flux is analyzed. The third experiment uses thermatic mapper (TM) data to look at the scaling of the normalized vegetation index (NDVI), latent heat flux, and sensible heat flux through either scaling of the TM-derived fields using the TM data or the fields derived from aggregated TM data.

In all three experiments it was found that the surface fluxes and land characteristics can be scaled, and that macroscale models based on effective parameters are sufficient to account for the small-scale heterogeneities investigated. The paper also suggests that the scale at which a macroscale model becomes valid, the representative elementary scale (REA), is on the order 1.5-3 correlation lengths, which for land processes investigated appears to be about 1000-1500 m. At scales less than the REA scale, exact patterns of subgrid heterogeneities are needed for accurate small-scale modeling.
\end{abstract}

\section{Introduction}

The complex heterogeneity of the land surface through soils, vegetation, and topography, all of which have different length scales, and their interaction with meteorological inputs that vary with space and time result in fluxes of energy and water whose scaling properties are unknown. Research into land-atmospheric interactions suggests a strong coupling between landsurface hydrologic processes and climate (Charney et al. 1977; Walker and Rowntree 1977; Shukla and Mintz 1982; Rowntree and Bolton 1983; Shukla et al. 1990; Sud et al. 1990). The issue of "scale interaction" for land-surface-atmospheric processes has emerged as one of the critical unresolved problems for the parameterization of climate models.

Understanding the interaction between scales has increased in importance when the apparent effects of surface heterogeneities on the transfer and water and energy fluxes are observed through remote sensing and intensive field campaigns like HAPEX and FIFE (Sellers et al. 1988). The ability to parameterize macroscale models based on field experiments or remotely sensed

Corresponding author address: Eric F. Wood, Water Resources Program, Department of Civil Engineering and Operations Research, Princeton University, Princeton, NJ 08544. data has emerged as an important research question for programs such as the Global Energy and Water Experiment (GEWEX) or the Earth Observing System (EOS). It is also important for the parameterization of the macroscale land-surface hydrology necessary in climate models, and crucial to our understanding of how to represent subgrid variability in such macroscale models.

Current land-surface parameterization schemes can be put into three groups. The first is best represented by the bucket hydrology based on the work of Budyko (1956), which forms the basis for current long-term climate simulation. The second group would be the aggregated models with biospheric processes. This group of models is represented by the Biosphere Atmosphere Transfer Scheme (BATS) (Dickinson 1984) and the Simple Biosphere Model ( $\mathrm{SiB}$ ) (Sellers et al. 1986 ) in which the vertical structure of the canopy is well represented and the spatial characteristics are assumed constant. Wood (1991) has referred to these as "constant canopy" models. The final group incorporates subgrid heterogeneity at varying levels of detail, from fractional areas (Abramopolous et al. 1988) to statistical distribution for the subgrid processes (Entekhabi and Eagleson 1989; Famiglietti and Wood 1991a). 
Current research suggests two competing approaches for handling subgrid heterogeneity. (i) The first approach is based on the belief that subgrid processes have significant effect on processes at GCM scales and that the nonlinearity in subgrid-scale processes prevents simple scaling. This approach is supported by the observations of sea breezes arising from the significantly different characteristics between land and water. Avissar and Pielke (1989) also found that heterogeneity in land characteristics resulted in sea-breeze-like circulations and significant differences in surface temperatures and energy fluxes across the patches. It is important to note that in their hypothetical domain the patches are large with respect to the size of the domain. In natural domains the scale of such patches is often much smaller, which may lead to lower variability across the domain. (ii) The second approach is to ignore the variability in subgrid processes and to represent these processes at larger scales through models with effective parameters. Similarly, one may use aggregated inputs to drive these "macroscale" processes models at the large scale. This is essentially the approach of the constant-canopy biospheric models, where horizontal variability is ignored. It is also the approach of using small-scale micrometeorological field studies for calibration (Sellers and Dorman 1987; Sellers et al. 1989).

In this paper a series of numerical experiments are reported on that investigate the scaling of land-surface processes-either of the inputs or parameters-and compare the aggregated processes to the spatially variable case. Three experiments will be reported. These are as follows. The first is the aggregation of the hydrologic response in a catchment due to rainfall during a storm event and due to evaporative demands during interstorm periods. The second set of experiments is the spatial and temporal aggregation of latent heat fluxes, as calculated from $\mathrm{SiB}$. The third set of experiments is the aggregation of remotely sensed land vegetation and latent and sensible heat fluxes using thermatic mapper (TM) data from the FIFE experiment of 1987 in Kansas.

\section{Aggregation of hydrologic responses}

Runoff generation is now known to result from a complexity of mechanisms; during a particular storm different mechanisms may generate runoff from different parts of a catchment. As reviewed in Wood et al. (1990), these mechanisms include runoff due to rainfall on areas of low-permeability soils (referred to as the infiltration excess mechanism) and from rainfall on areas of soil saturated by a rising water table even in high-permeability soil ( referred to as saturation excess runoff generation). These saturated contributing areas expand and contract during and between storm events.
As first shown by Beven and Kirkby (1979), variations in topography play a significant role in the spatial variation of soil moisture within a catchment, setting up spatially variable initial conditions for both runoff from rainstorms and evaporation during interstorm periods. Beven and Kirkby (1979) were the first to develop a saturated storm-response model (TOPMODEL). This model has been further expanded to include the above mechanisms (see Beven 1986a,b; Sivapalan et al. 1987). A complete description of the models, incorporating spatial variability in topography and soils, is provided in Wood et al. (1990) and will not be repeated here.

During interstorm periods, topography plays an important role in the downslope redistribution of soil moisture and, with soil properties, sets up the initial conditions for evaporation. The maximum evaporation rate is that rate demanded by atmospheric conditions, referred to as the potential rate, and this rate is met if the soil column can deliver the moisture to the surface. Rates lower than the potential rate will be at a "soil controlled" rate to be determined by soil properties and soil-moisture levels. The model with both storm and interstorm processes is fully described in Famiglietti et al. (1992).

The water-balance model described in Famiglietti et al. (1992) was applied to the Kings Creek catchment of the FIFE area in Kansas. Figure 1 shows the division of the $11.7 \mathrm{~km}^{2}$ catchment into subcatchments-the number ranging from 5 to 66 depending on the scale. All subcatchments represent hydrologically consistent units, in that runoff flows out of the subcatchment through one flow point and that the surface-runoff flux across the other boundaries is zero.

For a rainfall storm on 4 August 1987, the average runoff for the subcatchments was calculated for two times and plotted in Fig. 2 against a subcatchment area measured in pixels. Each pixel is $900 \mathrm{~m}^{2}$. Notice that the runoff $Q_{t}$ is normalized by the average precipitation, $\vec{P}$. The same type of plot was done for selected times during an interstorm period that extended from $18 \mathrm{July}$ through 31 July 1987 and is presented as Fig. 3. The behavior of the catchment shows that at small scales there is extensive variability in both storm response and evaporation. This variability appears to be controlled by variability in soils and topography whose length scales are on the order of $10^{2}-10^{3} \mathrm{~m}$-the typical scale of a hill slope. With increased scale, the increased sampling of hill slopes leads to a decrease in the difference between subcatchment responses. At some scale, the variance between hydrologic responses for catchments of the same scale should reach a minimum (Wood et al. 1990). Wood et al. (1988) suggest that this threshold scale represents a representative elementary area (REA), which is proposed to be the fundamental building block for hydrologic modeling, as defined in Wood et al. (1988) and Wood et al. (1990). 


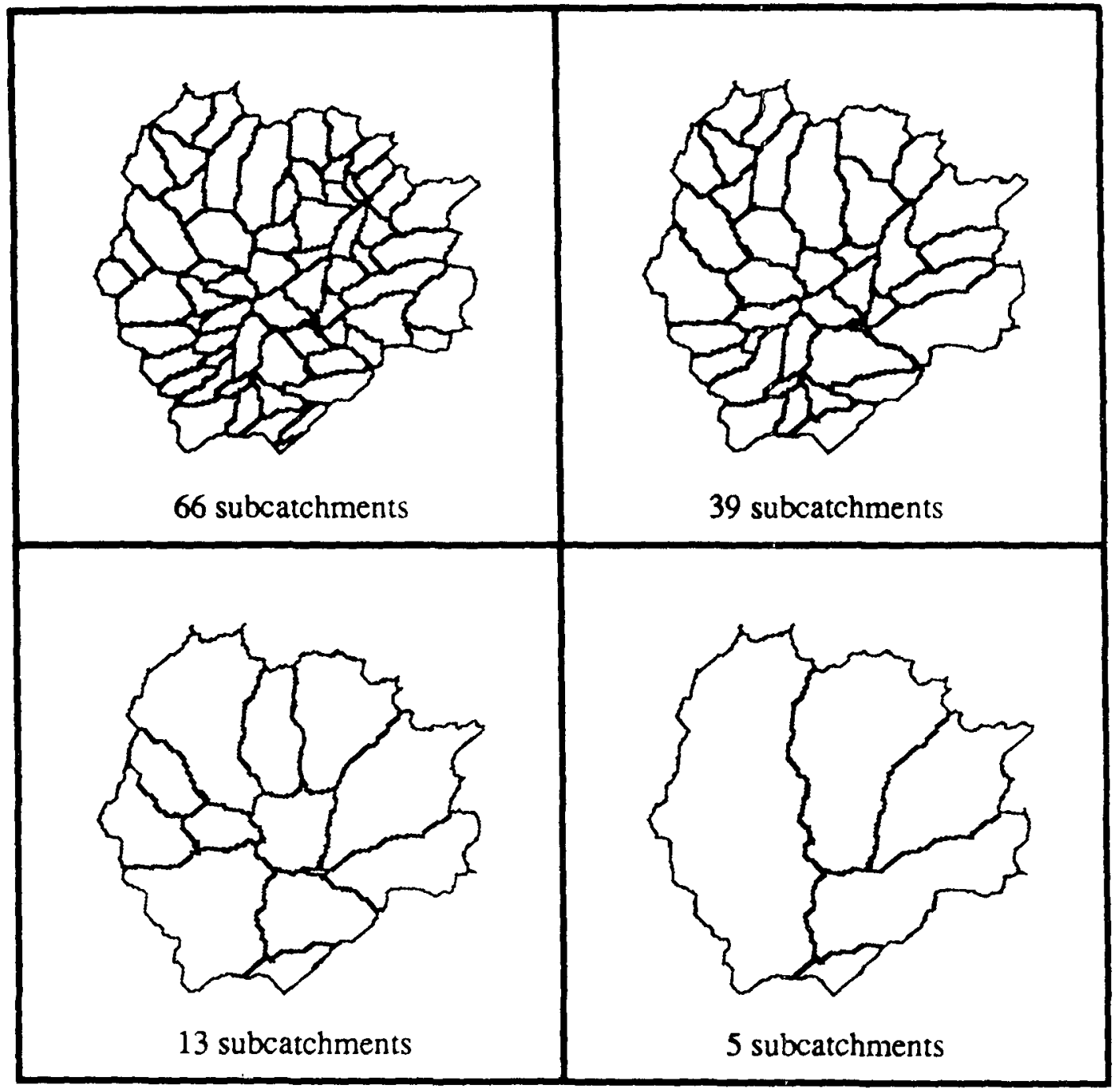

FIG. 1. Natural subcatchment divisions for Kings Creek, Kansas.

The REA is the critical scale at which implicit continuum assumptions can be used without explicit knowledge of the actual patterns of topographic, soil, or rainfall fields. It is sufficient to represent these fields by their statistical characterization.

By inspecting Figs. 2 and 3, it appears that the size of the REA is on the order of $1 \mathrm{~km}^{2}$ (about 1000-1200 pixels, each of which are $900 \mathrm{~m}^{2}$ ). The results also suggest that at larger scales it would be possible to model the responses using a simplified macroscale "model based on the statistical representation of the heterogeneities in topography, soils, and hydrologic forcings (rainfall and potential evaporation). To date, only a limited range of catchments has been analyzed, all having moderate topography and located in regions with humid climates. The REA scale appears to be quite consistent at about $1-2 \mathrm{~km}^{2}$ and to be the same scale for both runoff and evaporation processes. Clearly, additional catchments representing a broader range of climates and catchment sizes need to be analyzed before definitive statements concerning the REA scale can be made.

Using the statistical distribution of the topographicsoil index, one can determine the fraction of the catchment that will be saturated due to the local soil storage being full. These areas will generate saturation excess runoff at the rate $\bar{p}$, the mean rainfall rate. For that portion of the catchment where infiltration occurs, the local expected runoff rate at time $t, m_{q}$, can be calculated as the difference between the mean rainfall rate, $\bar{p}$, and the local expected infiltration rate, $m_{g}$. This implies that $m_{q}$ and $m_{g}$ are conditioned upon a topographic-soil index whose statistical distribution is central to the REA macroscale model. The difference be- 


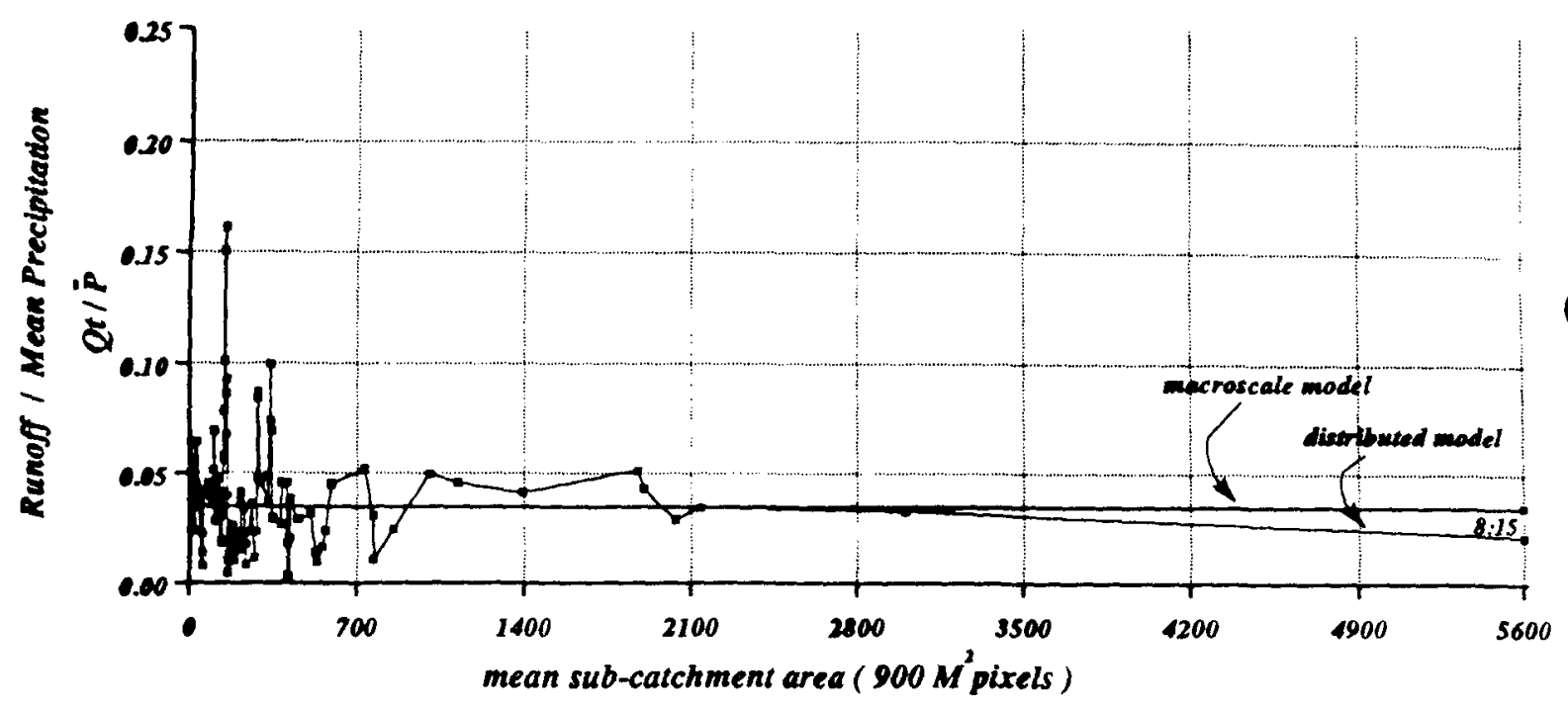

(a)

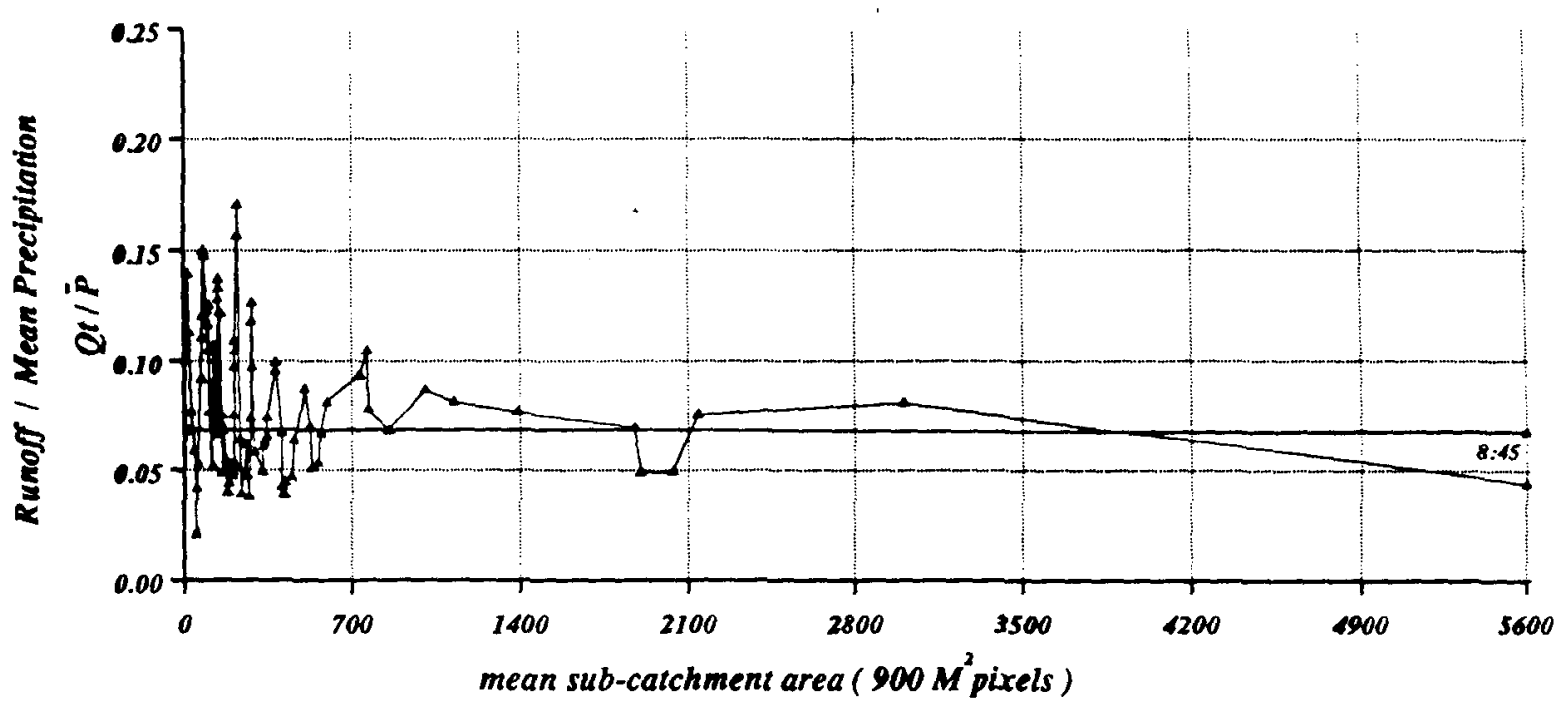

(b)

Fig. 2. Comparison of storm runoff generated from the distributed model and from the macroscale water-balance model for two time intervals on 4 August 1987: (a) 0845 LDT and (b) 0930 LDT.

tween averaged rainfall and infiltration can be expressed as

$$
\begin{aligned}
m_{q}\left[t \mid \ln \left(a T_{e} / T_{i}\right.\right. & \tan \beta)] \\
& =\bar{p}-m_{g}\left[t \mid \ln \left(a T_{e} / T_{i} \tan \beta\right)\right],
\end{aligned}
$$

where $\ln \left(a T_{e} / T_{i} \tan \beta\right)$ is the topographic-soil index for a location $i$ in the catchment and is a function of $\alpha$, the contributing area upslope to $i ; \tan \beta$, the local slope angle; $T_{i}$, the soil transmissivity at $i$; and $T_{e}$, the catchment average of $T_{i}$. As discussed above, $m_{q}$ and $m_{g}$ are time-varying functions whose values at any particular time are equal for points within the catchment having the same topographic-soil index; this dependance is indicated in Eq. (1) by the 1 . The full development of the topographic-soil index is provided in Beven and Kirkby (1979), Beven (1986a,b), Sivapalan et al. (1987), and Wood et al. (1990). Both the local expected runoff rate and the local expected infiltration rate are (probabilistically) conditioned on the topographic-soil index, $\ln \left(a T_{e} / T_{i} \tan \beta\right)$. The runoff production from the catchment is found by integrating, usually numerically, the conditional rate over the statistical distribution of topographic-soil index. Figure 2 also gives results for the macroscale model along with the distributed model. Since the macroscale model is scale invariant, it appears as a straight line in Fig. 2. 
Modeled Interstorm Evaporation Following Rain Ending 01:30 July 181987

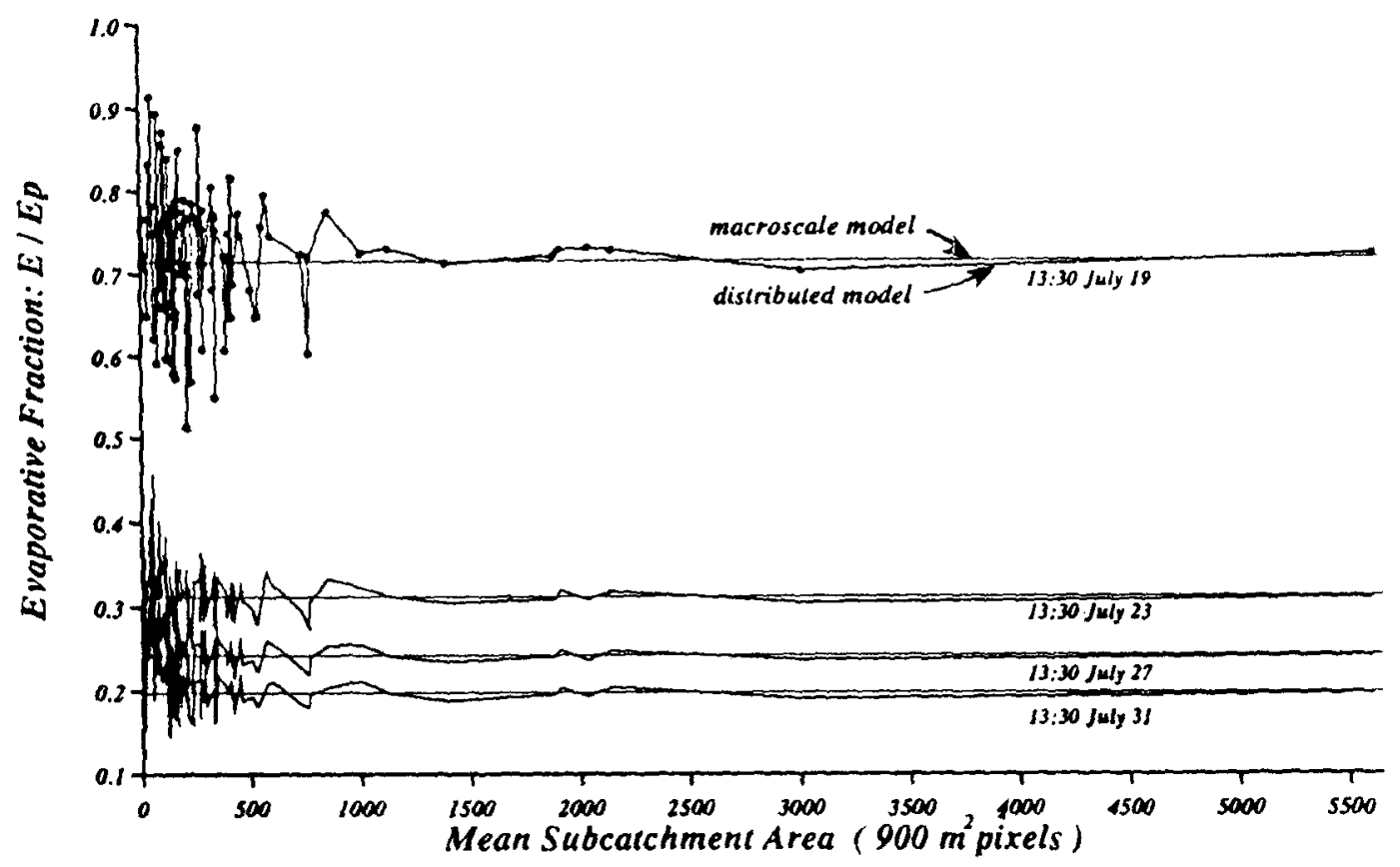

FIG 3. Comparison of interstorm evapotranspiration from the distributed model and from the macroscale water-balance model for four times during the 18-31 July 1987 interstorm period.

In a similar way, a macroscale evaporation model is developed for interstorm periods. As stated earlier, topography plays an important role in the interstorm redistribution of soil moisture. Variations in soil properties and topography lead to variations in soil moisture and the initial conditions for the evaporation calculations. For those portions of the catchment for which the soil column can deliver water at a rate sufficient to meet the potential evapotranspiration or atmospheric demand rate $E_{p}$, the actual rate $E$ equals $E_{p}$; otherwise, the rate will be at a lower soil-controlled rate $E_{s}$. Within the TOPMODEL framework, locations with the same value of the topographic-soil index will respond similarly, implying a macroscale model conditioned on that index. The macroscale model can be written as:

$$
\begin{gathered}
m_{E}\left[t \mid \ln \left(a T_{e} / T_{i} \tan \beta\right)\right]=\min \left\{m_{E_{s}}\right. \\
\left.\quad\left\{t \mid \ln \left(a T_{e} / T_{i} \tan \beta\right)\right], \bar{E}_{p}(t)\right\},
\end{gathered}
$$

where $m_{E}$ refers to the mean evaporation rate at locations in the catchment with the same index, $m_{E_{s}}$ refers to the mean soil-controlled rate, and $\bar{E}_{p}$ to the spatially average potential or atmospheric demand rate. Figure 3, which compares the evaporation rates from the distributed model across the range of scales for Kings Creek, also includes the derived rates from the macroscale evaporation model. As in Figure 2, the macroscale model is scale invariant and appears as a straight line.

\section{a. Summary on hydrological scaling}

The results from the REA analysis suggest that progress has been made in understanding the transition in hydrologic responses during storm and interstorm periods as scale is increased in the presence of spatial variability. In particular, the results indicate that the macroscale models that preserve the statistical characterization of the small-scale variability in the hydrologic controls (topography and soils) can accurately represent both storm and interstorm water fluxes. The results presented here are based on a specific model applied to the FIFE study site. Good agreement between model predictions and observations have been obtained (see Famiglietti and Wood 1991b; Famiglietti et al. 1992). The model representation of soil water movement (infiltration and evapotranspiration) is highly nonlinear, so we are confident that the scaling of these processes across a range of heterogeneous hill slopes and soils, which leads to the macroscale model, is reasonable. Nonetheless, the results presented here need to be expanded over a wider range of catchment and climatic scales to further verify the concepts of the representative elementary area.

\section{Spatial and temporal scaling using a biospheric transfer model}

The development of models that have biosphericatmospheric interactions is motivated by recent ad- 


\section{ATMOSPHERIC BOUNDARY LAYER}

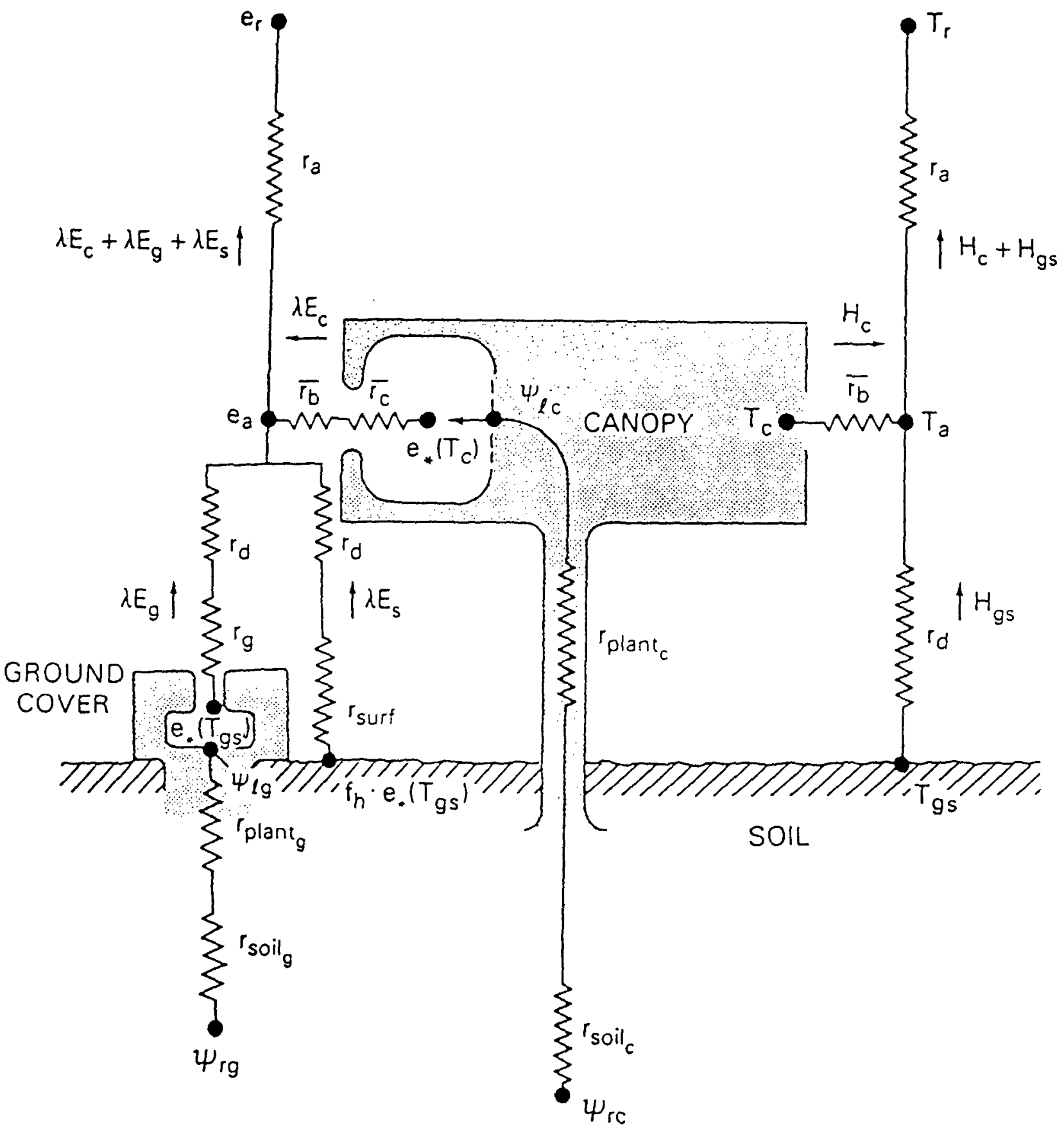

FIG. 4. Framework of the Simple Biosphere Model (SiB). The transfer pathways for the latent and sensible heat fluxes are shown on the left- and right-hand sides of the diagram, respectively. The treatment of radiation and intercepted water has been omitted for clarity. Symbols are as defined in Sellers et al. (1986) [ from Sellers et al. (1986)].

vances in plant physiology, micrometerology, and hydrology and our ability to integrate all of these smallscale physical processes that control biosphere-atmo- sphere interactions. Two of the most widely used models are the Simple Biosphere Model (SiB) (Sellers et al. 1986) and the Biosphere-Atmosphere Transfer 
Scheme (BATS) Model (Dickinson et al. 1986). The models attempt to separate the vegetation canopy from the soil surface and to represent the energy and water fluxes from the canopy in detail. Thus, the resulting models have a complex representation of the soil-vegetation-atmosphere system, which gives them the appearance of having tremendous vertical resolution and structure. On the horizontal scale, these models usually assume homogeneous conditions; that is, the parameters for the soil and vegetation properties are assumed constant within a GCM grid, thus ignoring spatial heterogeneity. This has lead to describing these models as "big-leaf" or "constant-canopy" models.

Figure 4 gives a schematic for the parameterization of SiB. As described by Sellers et al. (1986), the parameterization consists of a two-layer vegetation canopy whose elements and roots are assumed to extend uniformly throughout the GCM grid. From the prescribed physical and physiological properties of the vegetation and soil, the model calculates (i) the reflection, transmission, absorption, and emission of direct and diffuse radiation in the visible, near-infrared, and thermal wavelength intervals; (ii) the interception of rainfall and its evaporation from leaf surfaces; (iii) the infiltration, drainage, and storage of residual rainfall in the soil; (iv) the control of photosynthetically active radiation and the soil-moisture potential, inter alia, over the stomatal functioning and, thereby, over the return transfer of the soil moisture to the atmosphere through the root-stem-leaf system of the vegetation; and $(v)$ the aerodynamic transfer of water vapor, sensible heat, and momentum from the vegetation and the soil to a reference level within the atmospheric boundary layer. The model originally had seven prog-

\section{PROB}
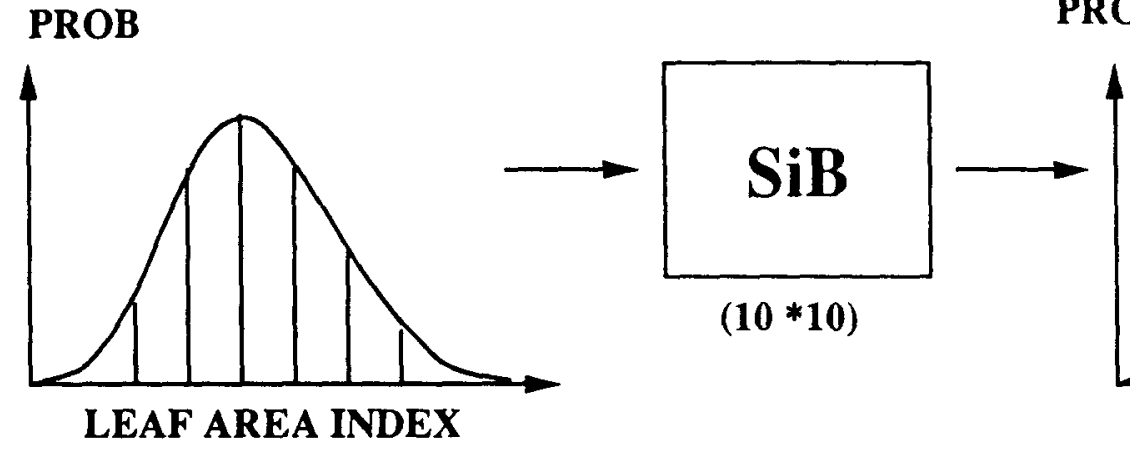

\section{PROB}

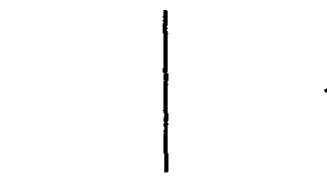

$(5 * 5)$
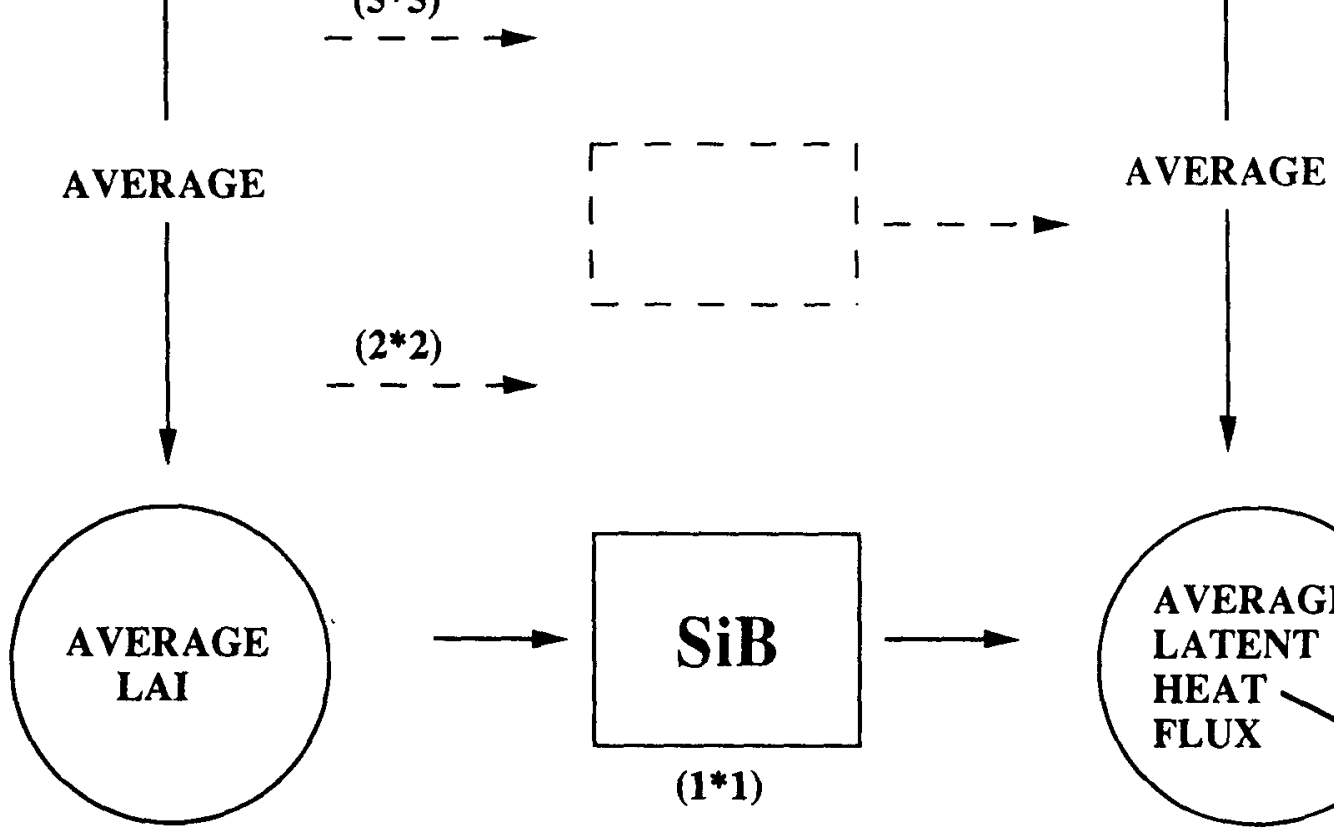

FiG. S. Schematic diagram for the biosphere-atmosphere scaling experiment. The spatially variable inputs and derived outputs are shown on the left- and right-hand sides of the diagram, respectively. Low aggregation to high aggregation of inputs are shown from top to bottom, respectively. 
nostic physical-state variables: two temperatures (a canopy temperature and ground temperature), two interception water storages (one for the canopy and one for the ground cover), and three soil-moisture storages of which two are for the two classes of vegetation and one for the soil recharge layer (Sellers et al. 1986). Recently an eighth prognostic variable was added for following the deep-soil temperature. $\mathrm{SiB}$ has been tested in a climate model by Sato et al. (1989) in which SiB is compared to the bucket model land-surface parameterization.

To investigate the effect of subgrid variability on the scaling of latent heat fluxes as derived from $\mathrm{SiB}$, the following numerical experiment was carried out. A gridded domain was defined in which the vegetation density (as described by its leaf-area index), precipitation, and initial soil wetness were allowed to be spatially variable. At the finest scale, a $10 \times 10$ grid, the scale of the grid $\left(L_{G}\right)$ divided by the scale of the domain $\left(L_{D}\right)$ is 0.1 . The average parameters for the domain were based on a calibration of SiB for data collected in Amazonia and reported in Sellers et al. (1989). The data consisted of 43 days of meteorological observations at a 1-h time interval.

The scaling analysis is presented schematically in Fig. 5. While all three variables were allowed to vary, Fig. 5 is simplified to show only the leaf-area index. Within the $10 \times 10$ domain, the random field for the spatially variable parameter is generated from a normal distribution with coefficient of variation of 0.25 . For the results presented here, spatial correlation was not included. SiB can then be run for each grid. This structure ignores any horizontal interaction among grids. From the $10 \times 10 \mathrm{SiB}$ runs, the probability distribution for the latent heat flux can be constructed.

Spatial scaling is investigated by averaging the inputs (leaf-area index, initial soil wetness, and rainfall) from adjacent grids. The levels considered were aggregated domains having $L_{G} / L_{D}$ ratios of 0.2 (a $5 \times 5$ gridded domain ), $L_{G} / L_{D}=0.5$, and $L_{G} / L_{D}=1.0$; the latter case being the spatially average, homogeneous case. Comparisons can be made between the derived latent heat fluxes from the aggregated inputs (the left-hand side of Fig. 5) and the averaging of the $10 \times 10$ (detailed) domain. If the inputs operate within $\mathrm{SiB}$ in a highly nonlinear manner, then the two averaging schemes would lead to a significant difference. The spatially averaged inputs would be biased compared to the spatially distributed parameter case.

Figure 6 shows the 43-day mean latent heat flux across the range of aggregations. In Fig. 6a, only the leaf-area index is varied, while all three inputs are varied in $6 \mathrm{~b}$. Figure 7 presents a scatterplot comparison between the hourly latent heat fluxes averaged over the $10 \times 10$ grid domain and the fluxes derived from the averaged inputs.

Three observations are in order. At the finest scale,
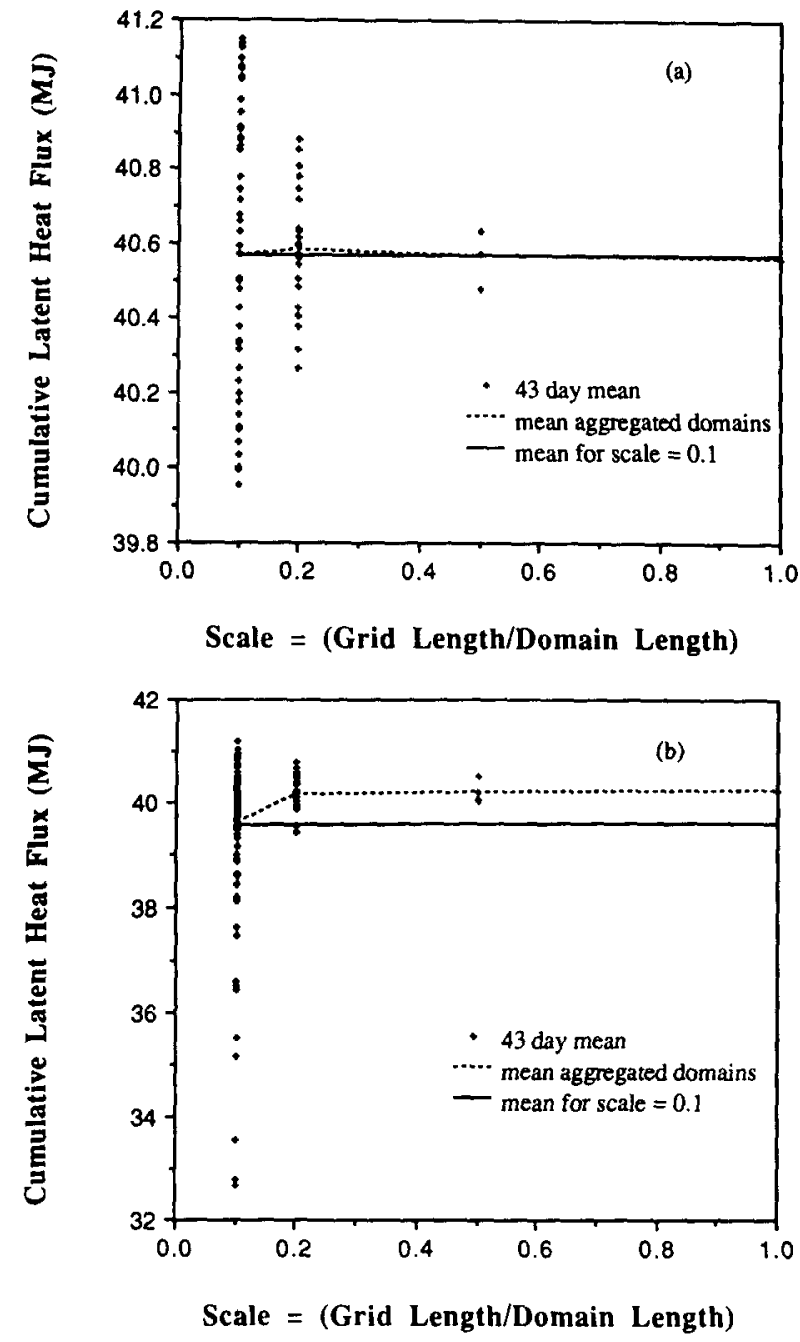

FIG. 6. Comparisons of latent heat fluxes, derived using $\mathrm{SiB}$, over a range of domain scales: (a) leaf-area index ( $\mathrm{LAI}$ ) spatially variable and (b) LAI, rainfall, and initial soil moisture variable. The fluxes were modeled using data from Sellers et al. (1989) and are shown as cumulative fluxes over $\mathbf{4 3}$ days.

$L_{G} / L_{D}=0.1$, there is substantial variability across the grids compared to the higher levels of aggregation. Nonetheless, the absolute range of variability is very small, given what we feel is a realistic range for the input variability. For the hourly data presented in Fig. 7 , the range of variability due to lumping is extremely small when compared to the range of calculated latent heat fluxes over the observation period. Second, a small bias is observed for the case where all three parameters are varying. This bias is due to the variability in initial soil wetness, the input parameter that appears to have the greatest influence on the average latent heat flux. Finally, we believe that the REA concept appears to hold for these experiments and is about $L_{G} / L_{D}=0.2$. In fact, subsequent analysis shows that the REA is re- 


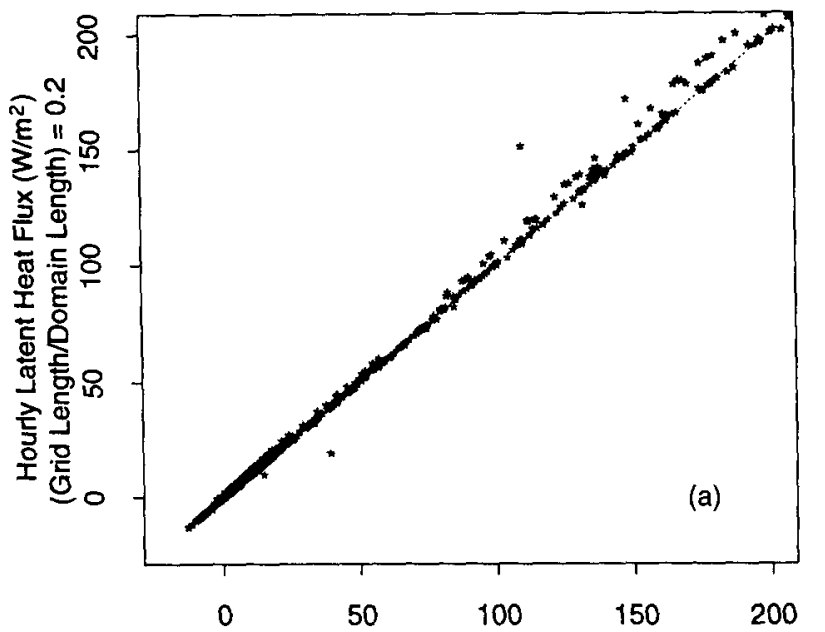

Hourly Latent Heat Flux $\left(\mathrm{W} / \mathrm{m}^{2}\right)$

(Grid Length/Domain Length) $=0.1$

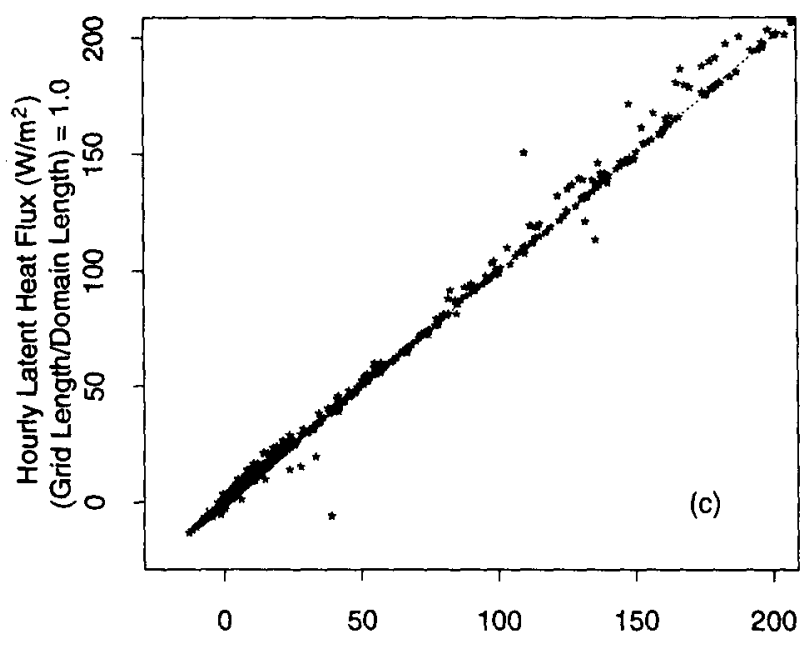

Hourly Latent Heat Flux $\left(W / \mathrm{m}^{2}\right)$

(Grid Length/Domain Length) $=0.1$

lated to the correlation length of the subgrid heterogeneities. Increased spatial correlation in the parameters leads to larger REAs. Further field studies are needed to establish realistic correlation lengths for these parameters.

The results presented in Figs. 6 and 7 used rainfall data at a temporal resolution of $1 \mathrm{~h}$. The effect of temporal averaging is shown in Fig. 8 with a scatterplot of the latent heat fluxes, as computed using hourly rainfall, and temporally averaged at either $2 \mathrm{~h}$ or $24 \mathrm{~h}$. The effect is a strong bias and variability between the two aggregation schemes. This demonstrates that temporal averaging of the rainfall input (which results in a reduction of rainfall intensity) has a significant impact on the surface water balance (runoff, soil moisture) and subsequent latent heat fluxes.

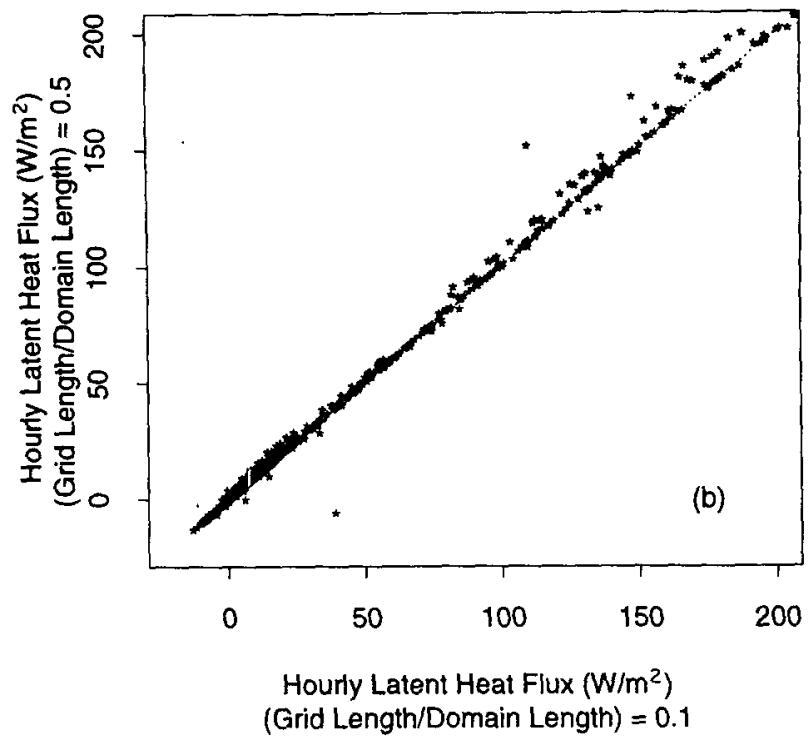

FIG. 7. Comparisons of cumulative latent heat flux between the distributed domain $\left(L_{G} / L_{D}=0.1\right)$ and aggregated domains for LAI, rainfall, and initial soil moisture spatially variable: (a) aggregated domain of $L_{G} / L_{D}=0.2$, (b) aggregated domain of $L_{G} / L_{D}=0.5$, and (c) aggregated domain of $L_{G} / L_{D}=1.0$.

\section{Scaling TM-derived surface variables}

The earlier two numerical experiments were concerned with scaling hydrologic and energy fluxes using a water-balance and land-surface biospheric model. In this third experiment, high-resolution thermatic mapper (TM) satellite data were used to derive the normalized difference vegetation index (NDVI), latent heat, and sensible heat fluxes for the 15 August 1987 overpass. The resolution of TM is $30 \mathrm{~m}$ for bands 1 through 5 , and $120 \mathrm{~m}$ for the thermal band that was used for the sensible and latent heat flux calculations.

The scaling question investigated here is whether averaging the TM bands prior to calculating NDVI or the fluxes provides the same derived quantities as would be found by calculating the quantities at the TM res- 

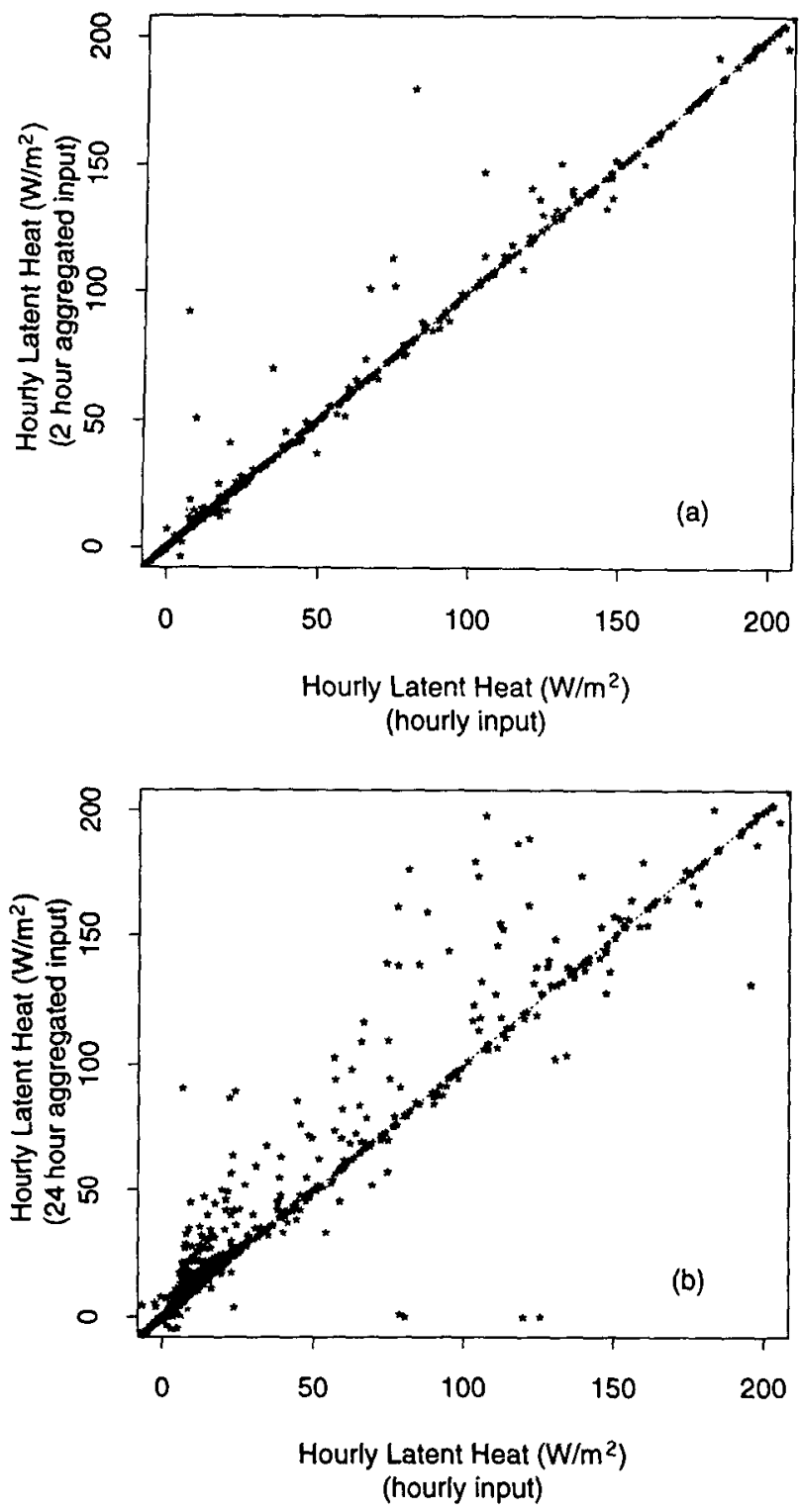

FIG. 8. Comparisons of cumulative latent heat flux between hourly rainfall and temporally averaged rainfall: (a) rainfall aggregated over $2 \mathrm{~h}$, (b) rainfall aggregated over $24 \mathrm{~h}$. The variables LAI, rainfall, and initial soil moisture are spatially constant.

olution and averaging. The equivalence of the two approaches depends on the degree of nonlinearity represented by functions that relate NDVI and fluxes to TM data.

\section{a. Scaling NDVI}

The following procedure was followed: the normalized difference vegetation index (NDVI) was calculated at the $30-\mathrm{m}$ TM resolution using

$$
\mathrm{NDVI}=\frac{\left(B_{4}-B_{3}\right)}{\left(B_{4}+B_{3}\right),}
$$

where $B_{3}$ represents band $3(0.63-0.69 \mu \mathrm{m})$, and $B_{4}$ represents band $4(0.76-0.90 \mu \mathrm{m})$. The first is often referred to as the red and the latter the near-infrared band. The NDVI image corresponding to a TM scene acquired over the FIFE area for 15 August 1987 is given in Fig. 9. The TM scene was fully calibrated before the calculations were carried out.

At aggregated scales, two procedures were followed. One was to spatially aggregate the TM bands and then use Eq. (3), while the second procedure is to spatially aggregate the NDVI based on the 30-m TM data. Figure 10 shows the aggregated NDVI, using the second procedure, for aggregation levels of $300 \times 300 \mathrm{~m}, 750$ $\times 750 \mathrm{~m}$, and $1500 \times 1500 \mathrm{~m}$. A resolution equivalent to AVHRR would lie between the last two cases. Comparisons between the two aggregation procedures can best be shown by a scatterplot between the aggregated 30-m-based NDVI and the NDVI derived using aggregated TM bands; these comparisons are presented in Fig. 11.

One striking observation arises from comparing Figs. 9 through 11 . Notice that the detailed structure observable in Fig. 9 is lost in Fig. 10, and yet the averaged NDVI from the two aggregation schemes are essentially the same as can be seen in scatterplot of Fig. 11. Figure 11 does show that a small bias exists between the two aggregation procedures but its magnitude is rather insignificant. These results indicate that NDVI calculated from spatially averaged TM (or lower-resolution AVHRR data) will be equivalent to the NDVI scaled up from the full-resolution image.

\section{b. Scaling up TM-derived latent and sensible heat fluxes}

Latent and sensible heat fluxes over the FIFE area during 15 August 1987 were estimated using the thermatic mapper (TM) thermal band (10.45-12.5 $\mu \mathrm{m}$, with a resolution of $120 \mathrm{~m}$ ) aboard Landsat 5 and a procedure presented by Holwill and Stewart (1992). The Landsat overflight was at 1632:50 UTC and the fluxes estimated for 1600-1700 UTC. The relationship between surface radiometric temperature and emittance is given for the Landsat thermal channel by Markham and Barker (1986) as

$$
T_{s}=K_{2} / \ln \left(K_{1} / R_{s}+1\right),
$$

where $R_{s}$ is surface emittance in $\left(\mathrm{W} \mathrm{m}^{-2} \mathrm{Sr}^{-1} \mu \mathrm{m}^{-1}\right)$, $K_{1}$ and $K_{2}$ are coefficients that, after atmospheric calibration for 15 August 1987, have values of $K_{1}=607.76$ $\mathrm{W} \mathrm{m}{ }^{-2} \mathrm{Sr}^{-1} \mu \mathrm{m}^{-1}$ and $K_{2}=1260.56 \mathrm{~K}$ (Goetz 1991, personal communication ).

The procedure developed by Stewart and Holwill (1992) combines the spatial TM thermal data with data 


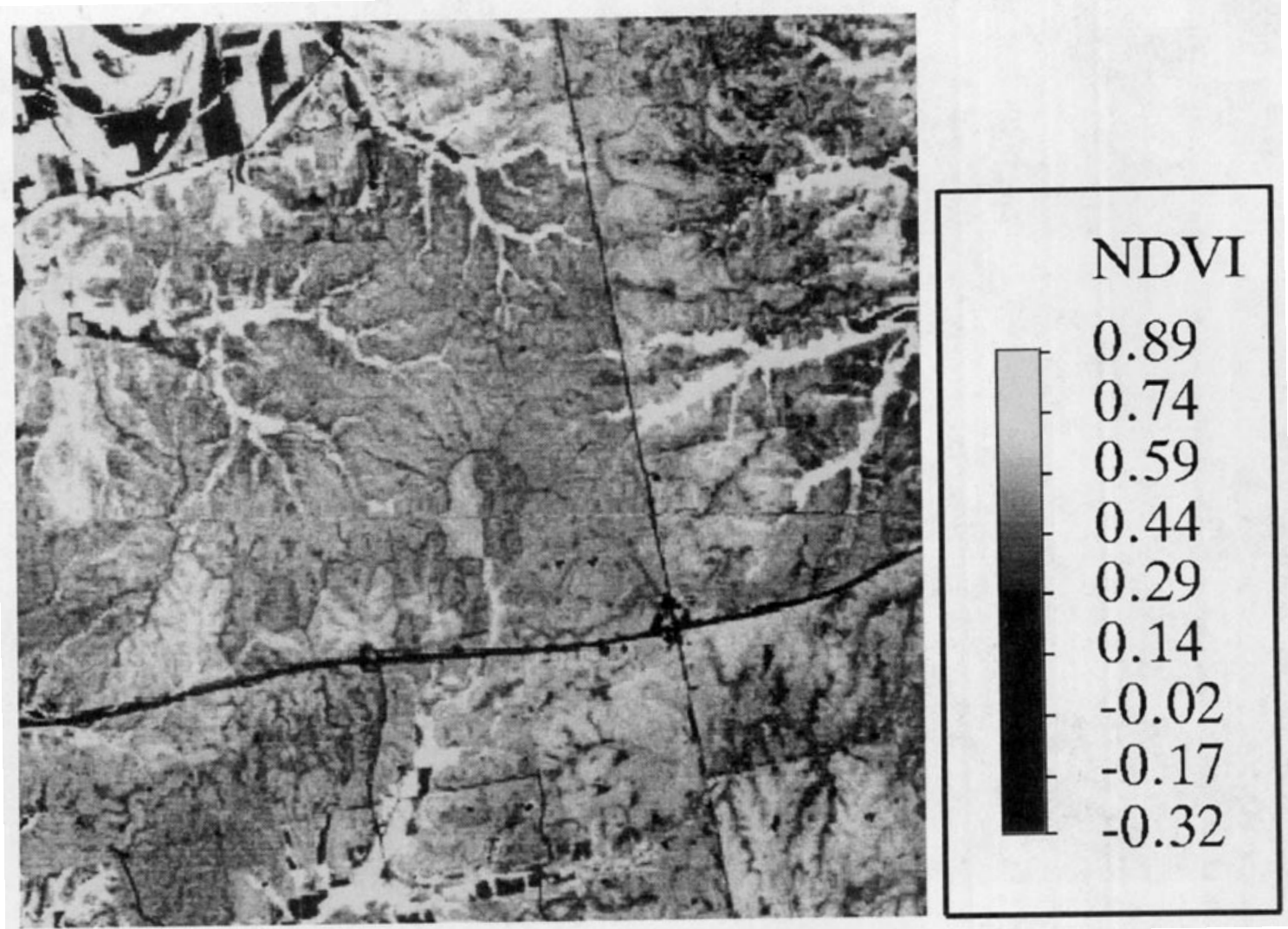

FIG. 9. Normalized vegetation index (NDVI) derived for part of the FIFE area from the 15 August 1987 overpass. Resolution is $30 \mathrm{~m}$.

at the surface flux measurement stations. A principal aim of the procedure is to extend the observations of sensible and latent heat fluxes spatially from the surface flux stations by combining the TM satellite thermal data with the station data. A TM-derived estimate of surface temperature was estimated for the locations within the FIFE area, corresponding to the different surface flux stations. In the $15 \mathrm{~km} \times 15 \mathrm{~km}$ FIFE area, there were 19 flux stations that were used in this analysis (see Sellers et al. 1989; Hall et al. 1992). The TM surface temperature estimates and the station sensible heat measurements can be combined to provide a transfer coefficient of the following form for the TM data:

$$
g_{s t}=\frac{H_{s t}}{\rho C_{p}\left(T_{s}-T_{a}\right)}
$$

where $\rho$ is air density $\left(1.19 \mathrm{~kg} \mathrm{~m}^{-3}\right), C_{p}$ is specific heat for air at constant pressure (at $25^{\circ} \mathrm{C}, 1005 \mathrm{~J} \mathrm{~kg} \mathrm{~K}^{-1}$ ), $H_{s l}$ is the observed station sensible heat, $T_{a}$ is the observed station air temperature, and $T_{s}$ the TM-derived surface temperature. Equation (5) is constructed so that $g_{s t}$ is equivalent to the inverse of the aerodynamic resistance term, assuming that all the variables on the right-hand side of (5) are measured accurately. The variable $g_{s t}$ can be interpreted as an "effective" coef- ficient that represents not only the aerodynamic resistance but also the effect of errors in $T_{s}$ and measurement errors in $H_{s t}$. The latter two may be quite large (Smith et al. 1992; Hall et al. 1992). In the analysis by Hall et al. (1992), they found that the TM-derived surface temperatures are high by about $3^{\circ} \mathrm{C}$, which is sufficient to result in large errors in computed sensible heat fluxes.

The $19 g_{s t}$ factors were interpolated across the 15 $\mathrm{km} \times 15 \mathrm{~km}$ FIFE area through geostatistical kriging. Similarly, $T_{a}$ was also interpolated across the site. Using this field and the TM-derived surface temperature (both at a $120-\mathrm{m}$ resolution), the sensible heat flux can be estimated over the domain by inverting (5). This allowed the estimation of the sensible heat across the FIFE area in a manner that is consistent with surface flux station observations. This field is referred to herein as $H_{d}$.

The TM-derived latent heat flux was estimated assuming that the sum of the averaged latent and sensible heat fluxes for the station data and the TM-derived fluxes would be equal.

While the above procedure could be refined, the resulting spatial patterns of sensible and latent heat fluxes appear to reflect quite accurately the underlying features within the FIFE area. Figures 12 and 13 give the 

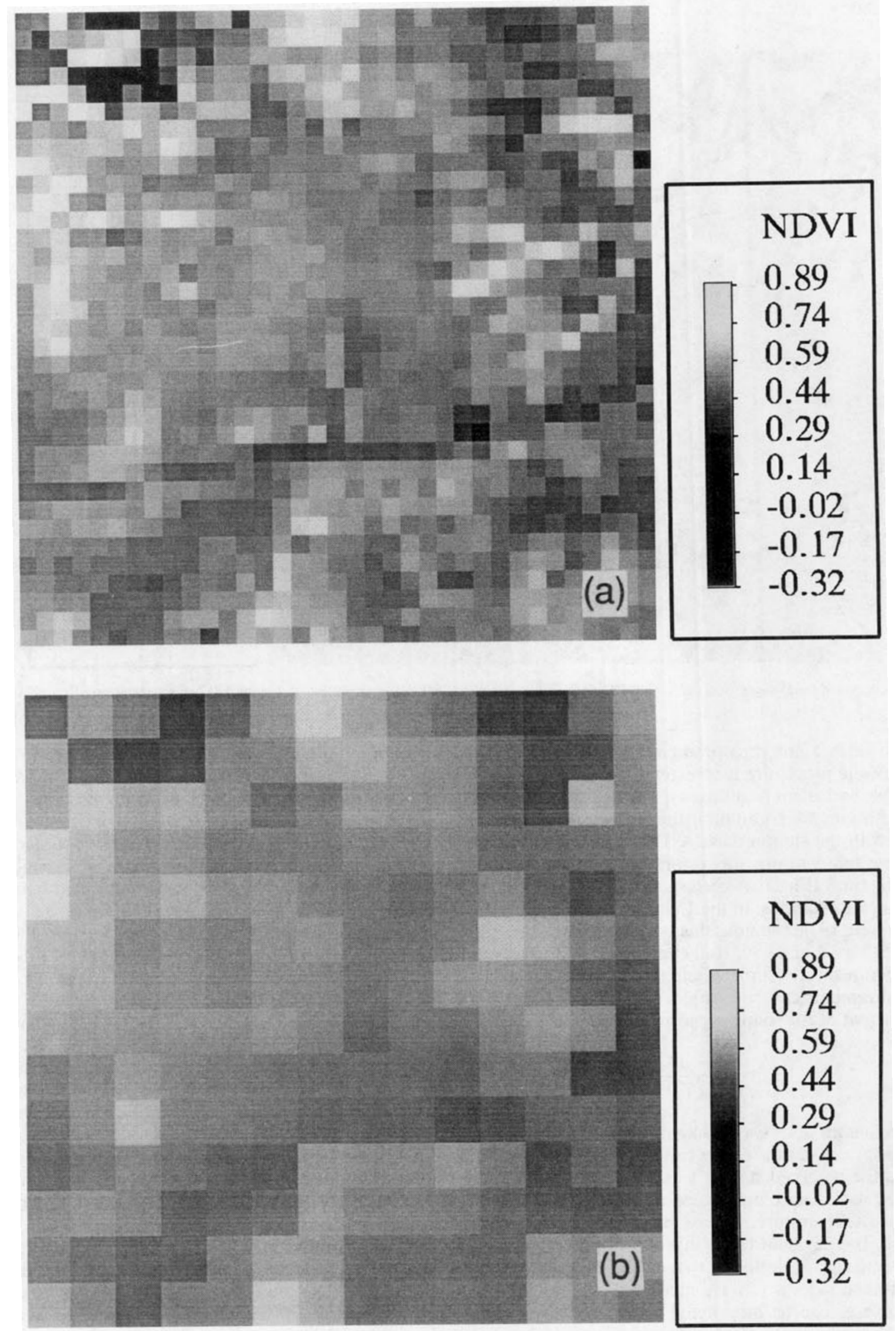

FIG. 10. Aggregated normalized vegetation index (NDVI) for part of the FIFE area for 15 August 1987. The images were derived using data from Fig. 9 . Levels of aggregation into each are (a) $300 \mathrm{~m} \times 300 \mathrm{~m}$, (b) $750 \mathrm{~m} \times 750 \mathrm{~m}$, and (c) $1500 \mathrm{~m} \times 1500 \mathrm{~m}$. 


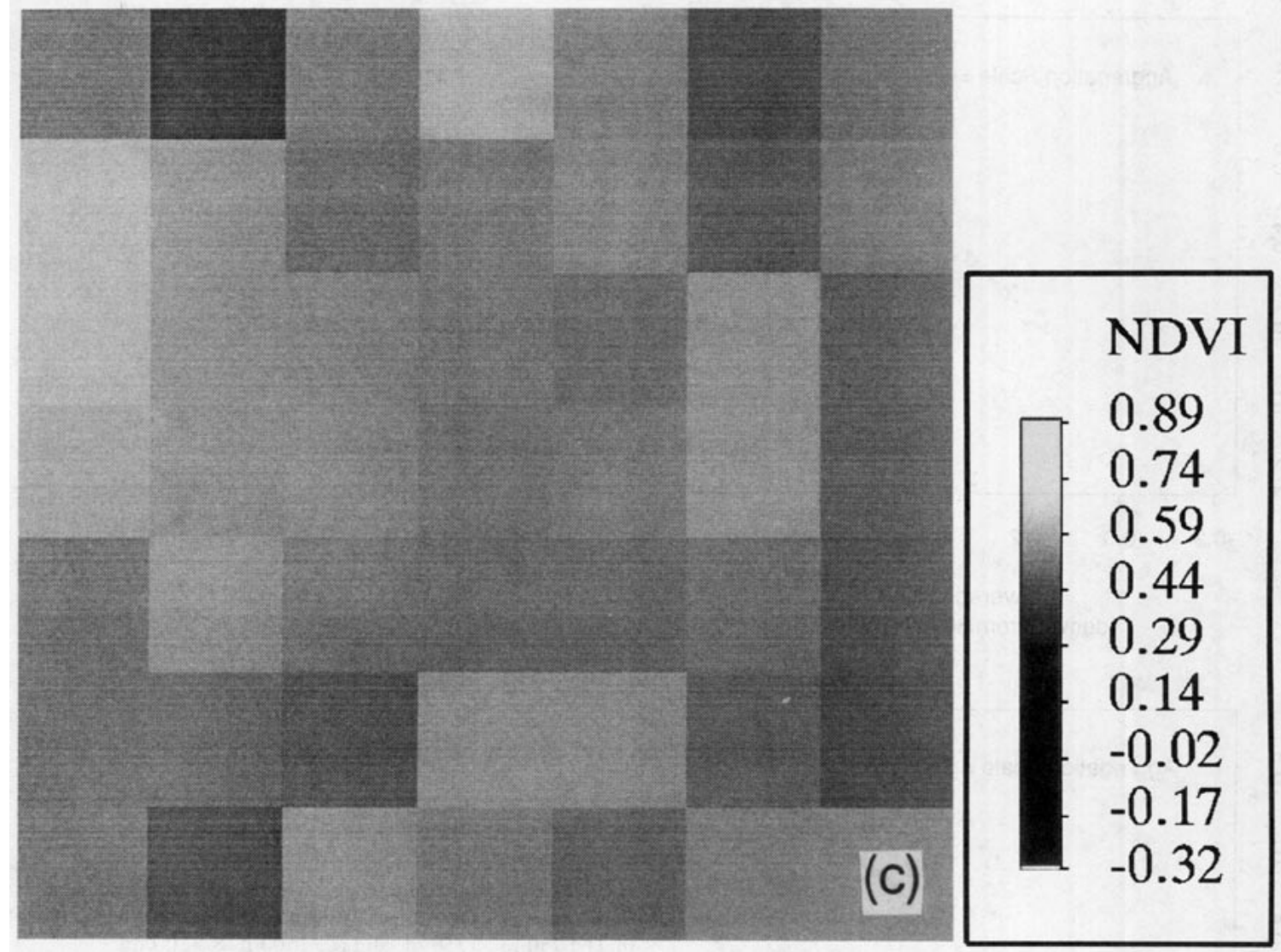

FIG. 10. (Continued)

derived images. Notice that the heavy vegetation in the southwest portion of the area (lower left) show up as having low sensible heat and high latent heat fluxes, as one would expect. Also, the interstate highway that crosses the area (east-west) can also be seen quite clearly. Some effect of the kriging can be seen as striping within the image.

The estimates in Figs. 12 and 13 are based on the TM surface radiances at a $120-\mathrm{m}$ resolution. The images were also calculated using radiances that were first aggregated five times (into $600 \mathrm{~m} \times 600 \mathrm{~m}$ pixels) and aggregated 25 times (into $3000 \mathrm{~m} \times 3000 \mathrm{~m}$ pixels). Using these aggregated resolutions, the sensible and latent heat fluxes were calculated over the FIFE area in the same manner as for the 120 -m data. Figures 14 and 15 present the aggregated images for sensible and latent heat fluxes.

Scatter plots comparing the aggregated fluxes (using the $120-\mathrm{m}$ thermal data) and the derived fluxes, based on aggregated radiances, are presented in Figs. 16 and 17 for the case when the level of aggregation was 25 times. These figures show that the scaling of thermal radiances prior to estimating scaled sensible and latent heat fluxes results in the same derived fluxes as obtained from scaling up small-scale derived fluxes; that is, the scaling of sensible and latent heat fluxes is linear, at least for the 15 August 1987 FIFE TM data. Figures 18 and 19 show the variability across FIFE, with different levels of aggregation for sensible and latent heat fluxes. Also shown are the means derived from the detailed image (solid line) but based on the aggregated image (dashed line). For both images (and especially the latent heat fluxes shown in Fig. 19), it is essentially impossible to differentiate these two means, indicating that the scaling is linear.

\section{Results and discussion}

The purpose of this paper is to review recent results for the scaling of water and energy fluxes from the land component of the climate system. Three sets of experiments were presented. The first was the hydrologic response at the scale of a catchment (but could easily be at a GCM grid scale), in which spatial variability in topography, soils, and hydrologic inputs (rainfall, in this case) resulted in spatially variable responses.

The second experiment was the application of $\mathrm{SiB}$ to a spatially heterogeneous domain based on data from Amazonia. Here, the experiments studied the impacts of variability in vegetation density (through the leafarea index ), initial soil wetness, and rainfall (both spa- 

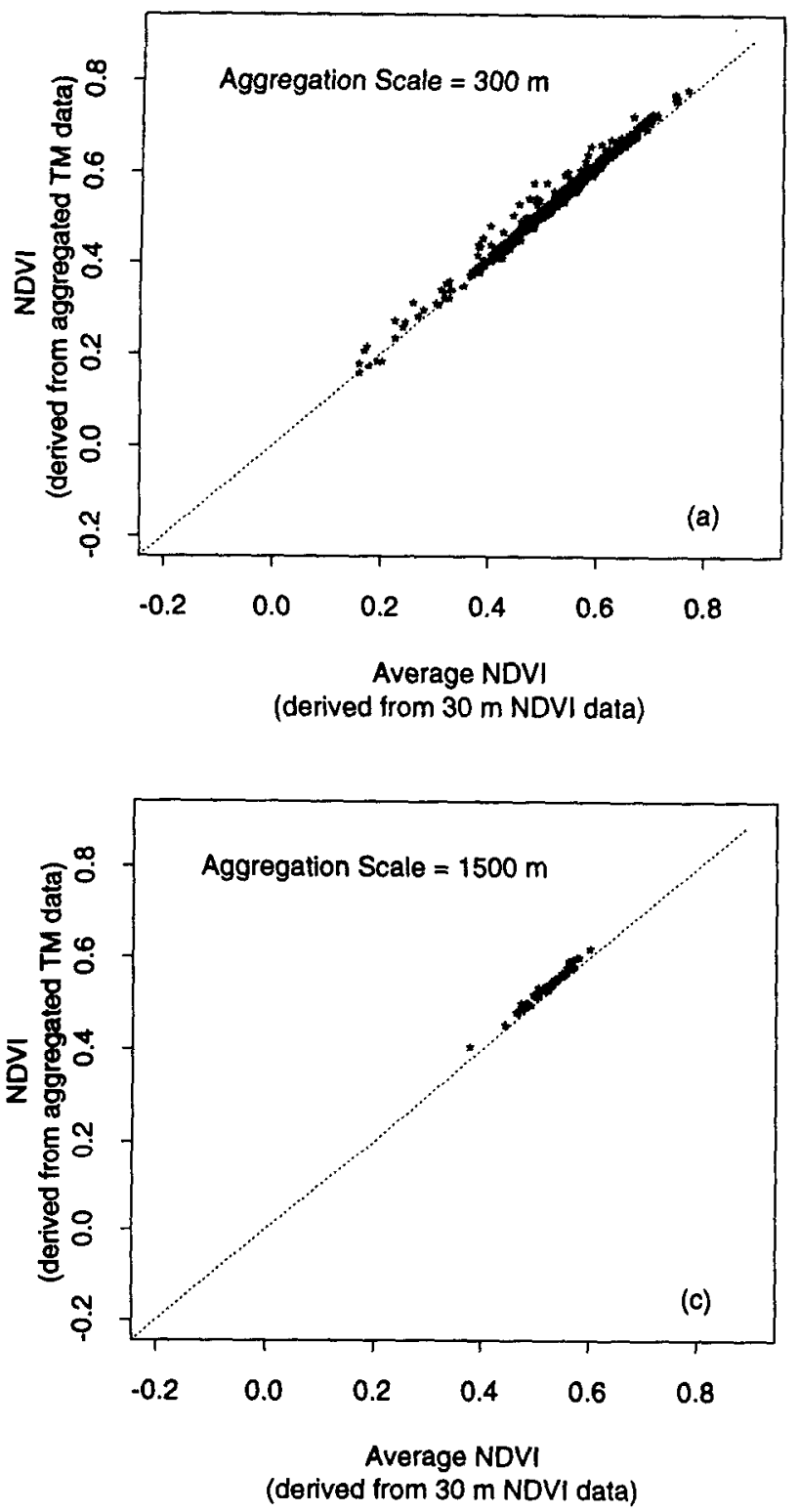

tially and temporally) on the derived latent heat flux over a 43-day observation period.

The third set of experiments studied the scaling in the normalized vegetation index (NDVI) and sensible and latent heat fluxes as derived from a thermatic mapper (TM) overpass of the FIFE area on 15 August 1987. Variations in surface conditions due to vegetation characteristics, as well as topography and soils, lead to significant variations in the TM-derived variables, as is shown in the presented images.

The major result from the three sets of experiments is that the scaled fields are equivalent to the fields derived from scaled inputs and parameters. The implication of this result is that the fluxes and land characteristics essentially scale linearly. More importantly,

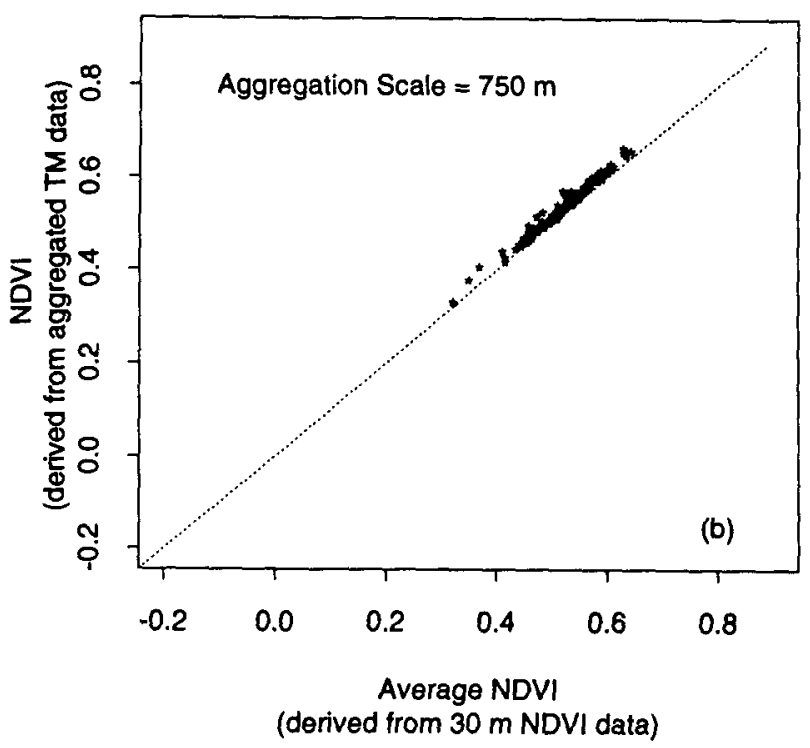

FIG. 11. Comparisons between NDVI derived from aggregated NDVI data of Fig. 9 and derived from Eq. (3) using aggregated thermatic mapper (TM) data. Levels of aggregation are (a) $300 \mathrm{~m} \times 300$ $\mathrm{m}$, (b) $750 \mathrm{~m} \times 750 \mathrm{~m}$, and (c) $1500 \mathrm{~m} \times 1500 \mathrm{~m}$.

these results appear to suggest that "equivalent" parameters can be used in scaled models (or macroscale models) for the calculation of spatially averaged quantities as long as the equivalent parameters reflect the statistical characteristics of the subscale variability. The one exception to this result was the temporal averaging of rainfall in the $\mathrm{SiB}$ experiment. In this case, the temporally averaged latent heat fluxes were significantly different from the latent heat fluxes derived from the temporally averaged rainfall. This implies that the latent heat scales nonlinearly with respect the rainfall rates.

These results must be balanced with the knowledge that the experiments presented were neither exhaustive nor complete. The modeling results with $\mathrm{SiB}$ did not 

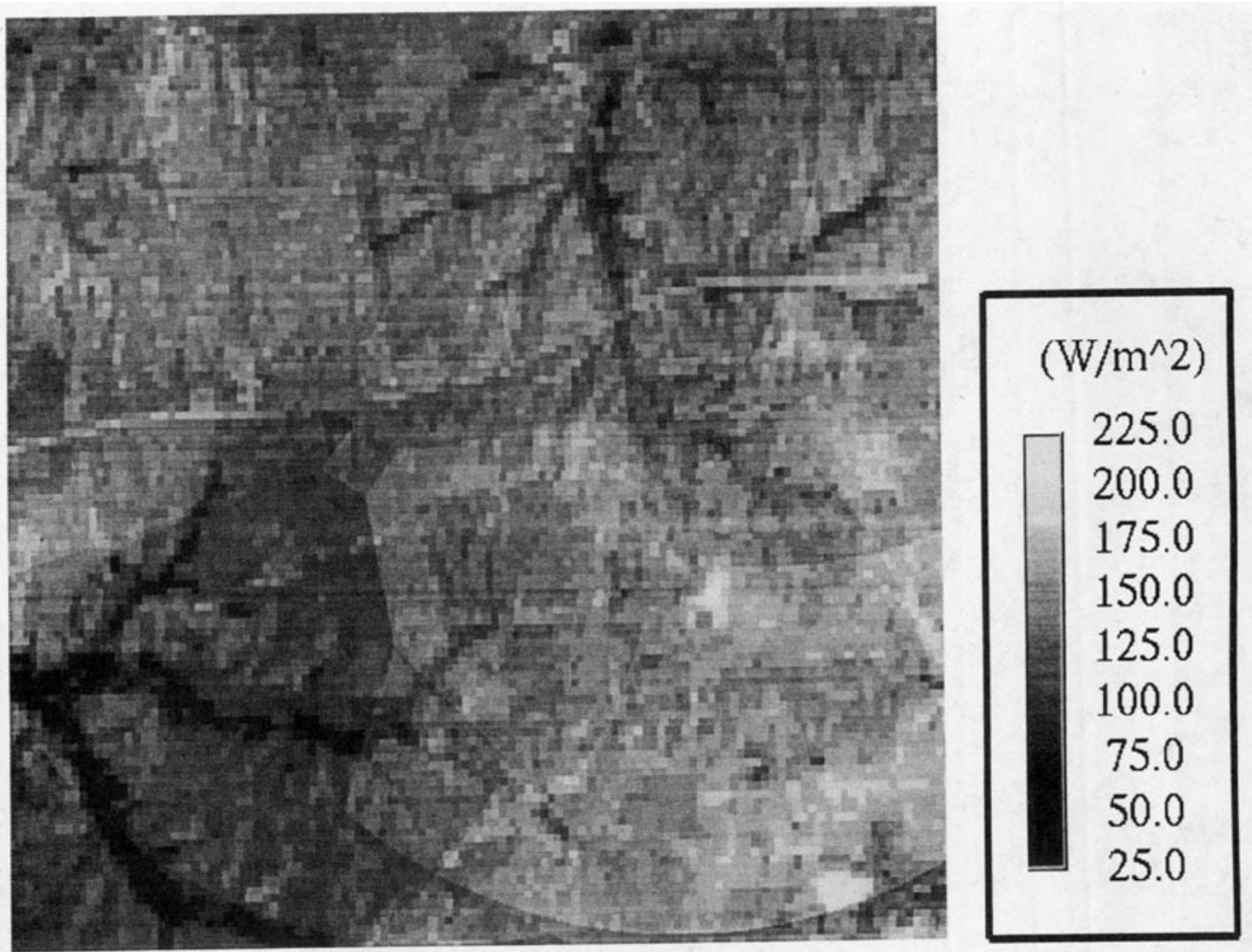

FIG. 12. Sensible heat flux for the FIFE area. The data are averaged over 15 August 1987 and are derived from the thermatic mapper (TM) overpass. Resolution is $120 \mathrm{~m}$.
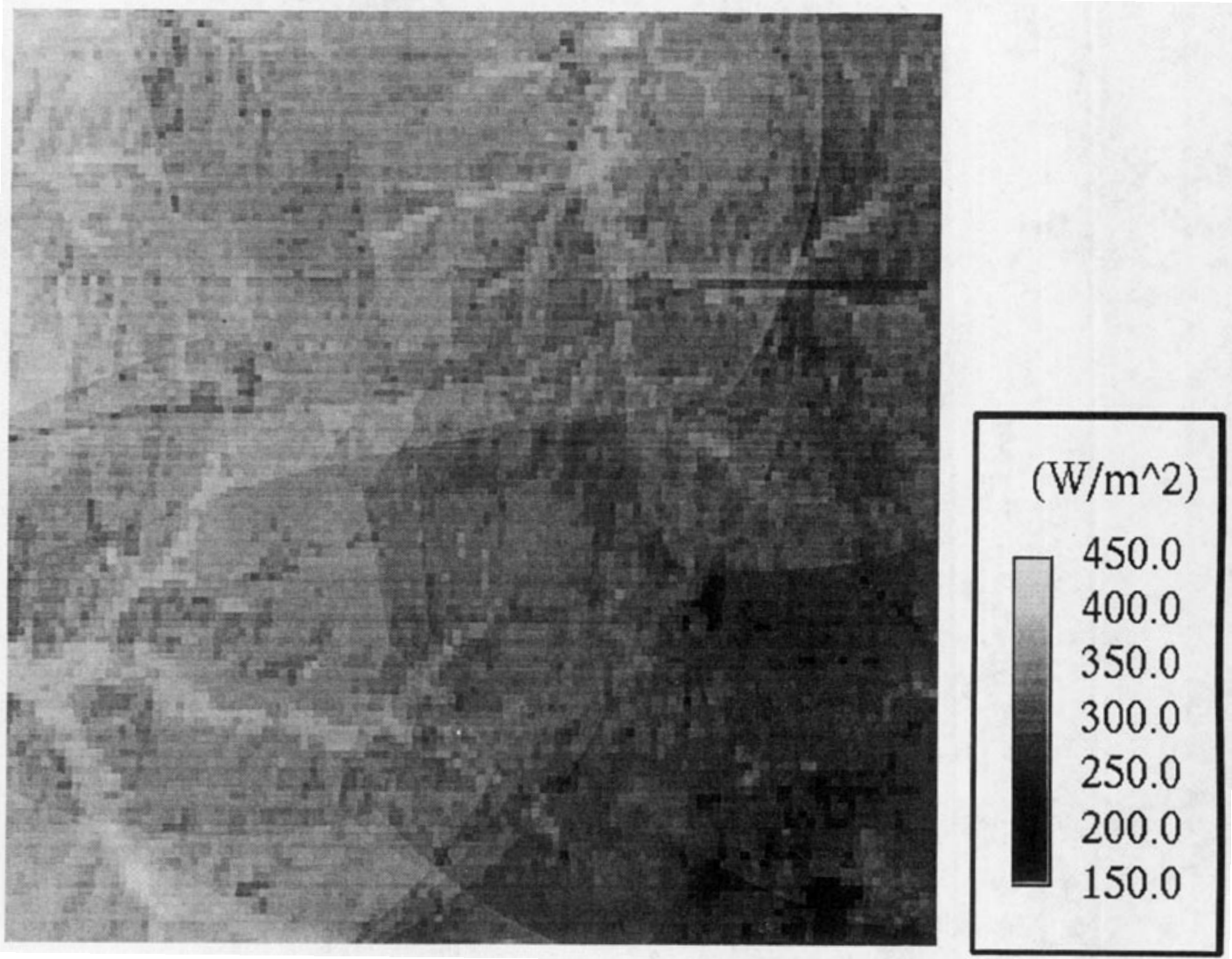

FIG. 13. Latent heat flux for the FIFE area. The data are averaged over 15 August 1987 and are derived from the thermatic mapper (TM) overpass. Resolution is $120 \mathrm{~m}$. 

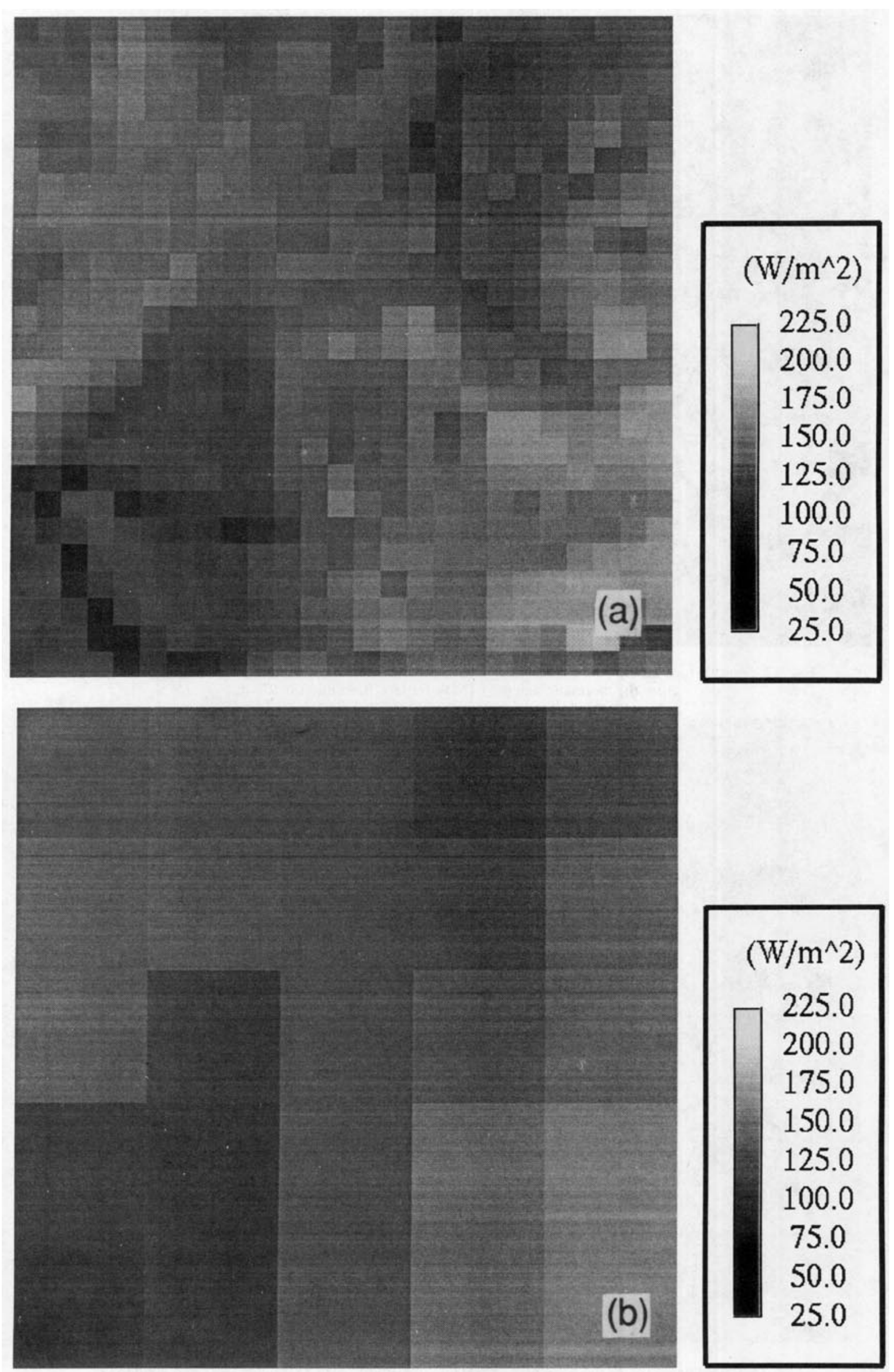

FIG. 14. Aggregated sensible heat flux for the FIFE area using data from Fig. 12. Levels of aggregation are (a) $600 \mathrm{~m} \times 600 \mathrm{~m}$ and (b) $3000 \mathrm{~m} \times 3000 \mathrm{~m}$. 

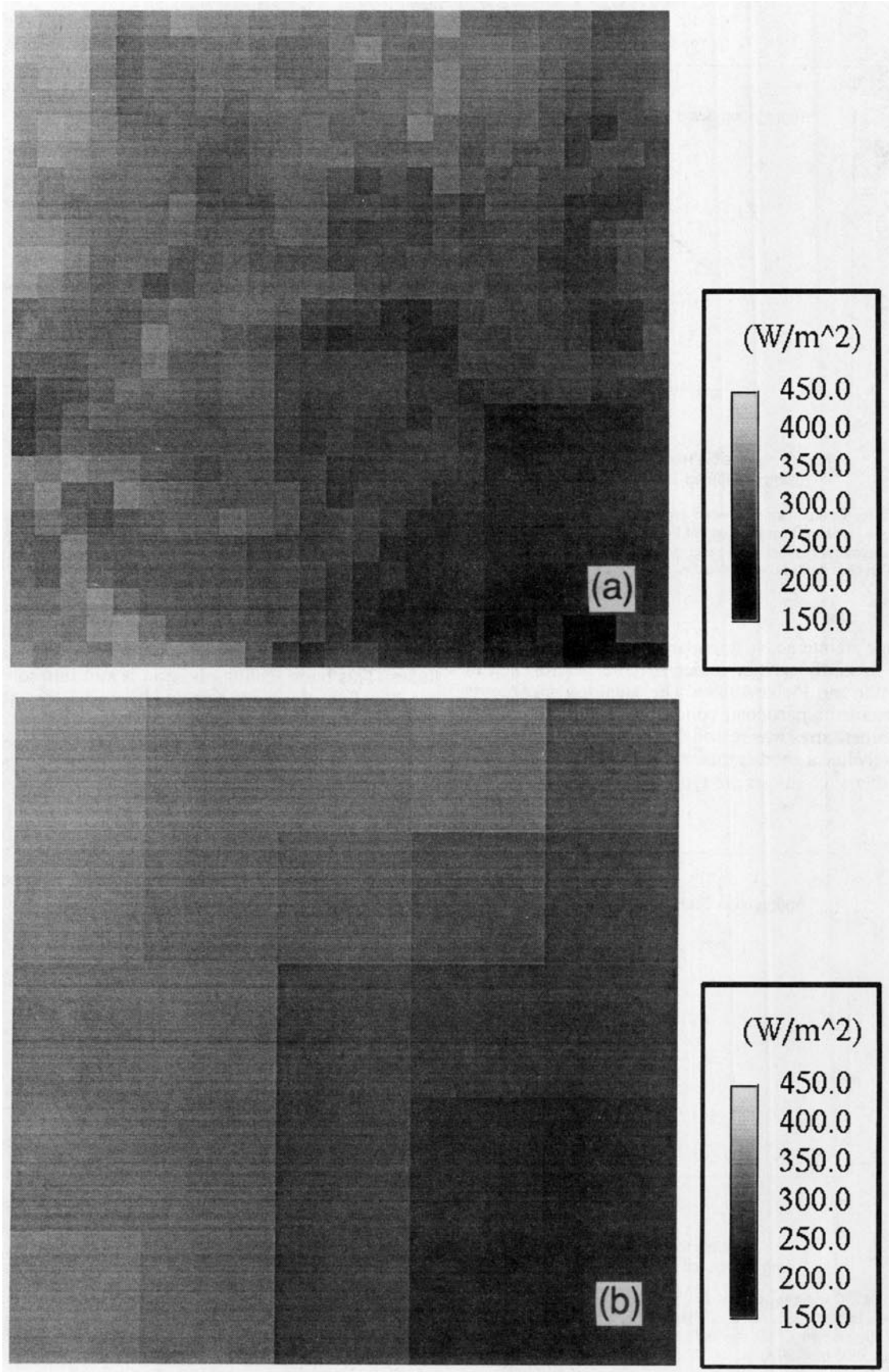

FIG. 15. Aggregated latent heat flux for the FIFE area using the data from Fig. 13. Levels of aggregation are (a) $600 \mathrm{~m} \times 600 \mathrm{~m}$ and (b) $3000 \mathrm{~m} \times 3000 \mathrm{~m}$. 


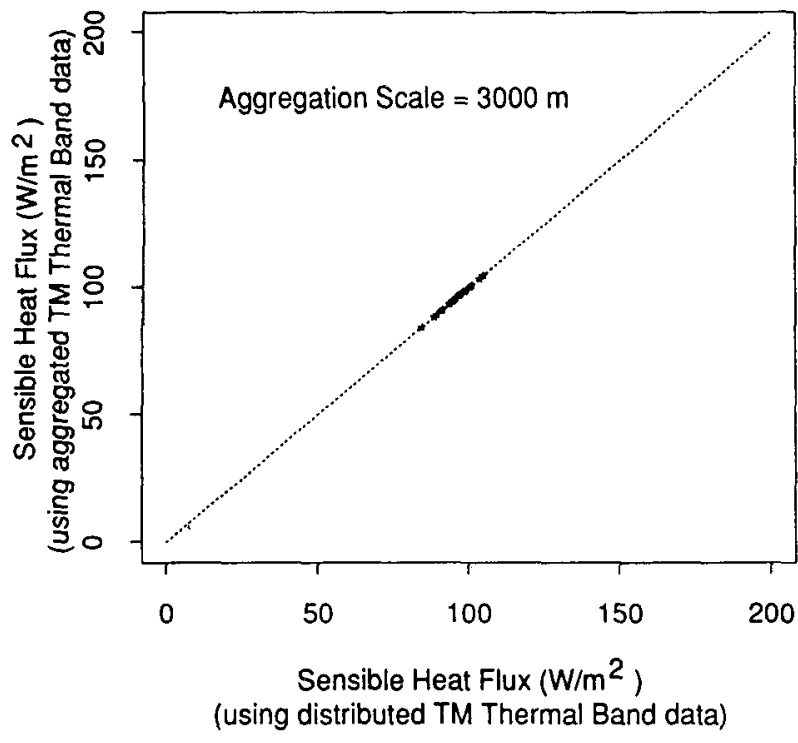

FIG. 16. Comparisons between sensible heat flux derived from aggregated sensible heat flux data of Fig. 12 and derived from aggregated thermatic mapper (TM) thermal-band radiances at an aggregation level of $3000 \mathrm{~m} \times 3000 \mathrm{~m}$.

include an interactive boundary layer whose effects can lead to nonlinearities under specific heterogeneities (Avissar and Pielke 1989). The satellite experiments represented a particular condition in which the range of temperatures was reasonably small, resulting in effectively linear models that transfer radiances to fluxes. Whether such ranges are typical of natural systems is

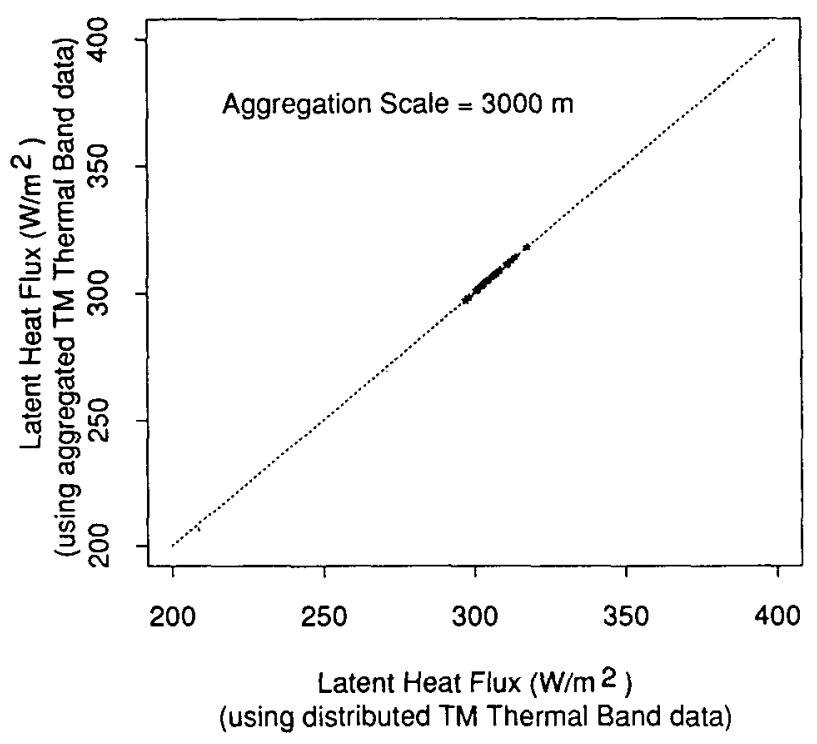

Fig. 17. Comparisons between latent heat flux derived from aggregated latent heat flux data of Fig. 13 and derived from aggregated thermatic mapper (TM) thermal-band radiances at an aggregation level of $3000 \mathrm{~m} \times 3000 \mathrm{~m}$.

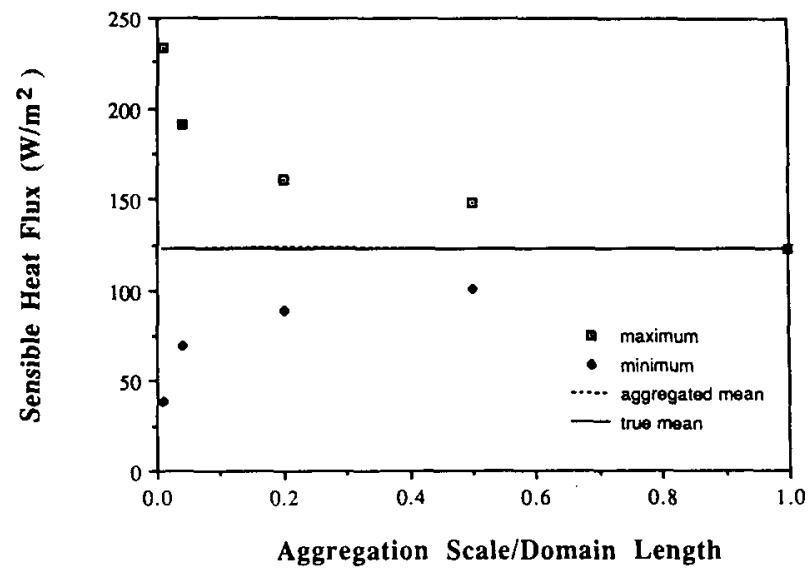

FIG. 18. Effect of aggregation on the variability of sensible heat across the FIFE domain for the 15 August 1987 TM overpass.

unknown until a greater number of analyses are done.

In the Introduction it was suggested that there were two current thoughts concerning subgrid variability: (i) that subgrid processes have a significant, nonlinear effect on large-scale processes that prevents simple scaling, and (ii) effective parameters within an appropriate macroscale model can represent large climatic fluxes. This basic scaling question is still unresolved, but hopefully the work presented here has provided some insight into these issues.

In the hydrologic-response experiment, the concept of the representative elementary area (REA) (Wood et al. 1988) was used to find the scale in which the macroscale model is a valid model for the scaled process. The results of the experiments carried out here suggest that the REA concept has wide applicability for a range of climate problems, and that it appears that the REA will be on the order of a few ( 1.5 to 3 )

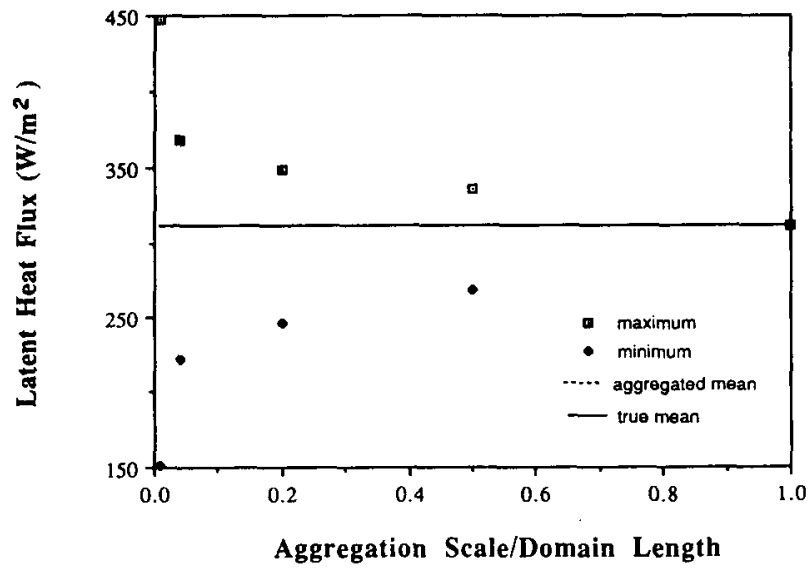

FIG. 19. Effect of aggregation on the variability of latent heat across the FIFE domain for the 15 August 1987 TM overpass. 
correlation lengths of the dominant heterogeneity. At scales larger than the REA scale, there has been enough "sampling" of the heterogeneities that the average response is well represented by a macroscale model with average parameters.

It is hoped that the experiments presented in this paper motivate related research, possibly with more complex land-atmospheric models or through a wider range of satellite data, that can help resolve the basic issue concerning scaling in natural systems. What must be determined are the scaling properties for reasonably sized domains in natural systems, where the range of variability (in vegetation, rainfall, radiance, topography, soils, etc.) is reflective of these natural systems. The results in this paper provide one perspective.

Acknowledgments. The research presented here was supported in part by the National Aeronautics and Space Administration (NASA) through Grants NAGW-1392 and NAG-899; this support is gratefully acknowledged. The authors also wish to thank Jay Famiglietti who helped develop the water-balance model for Kings Creek and Dom Thongs for helping with running the model and with the graphics.

\section{REFERENCES}

Abramopoulos, F., C. Rosenzweig, and B. Choudhury, 1988: Improved ground hydrology calculations for global climate models (GCMs): Soil water movement and evapotranspiration. $J$ Climate, 1, 921-941.

Avissar, R., and R. A. Pielke, 1989: A parameterization of heterogeneous land surface for atmospheric numerical models and its impact on regional meteorology. Mon. Wea. Rev., 117, 21132136.

Beven, K. J., 1986a: Runoff production and flood frequency in catchments of order $n$ : An alternative approach. Scale Problems in Hydrology, V. K. Gupta, I. Rodriguez-Iturbe, and E. F. Wood, Eds., D. Reidel, 107-131.

- $1986 \mathrm{~b}$ : Hillslope runoff processes and flood frequency characteristics. Hillslope Processes, A. D. Abrahams, Ed., George Allen and Unwin, 187-202.

- , and M. J. Kirkby, 1979: A physically based variable-contributing area model of basin hydrology. Hydrol. Sci. Bull., 24, 4369.

Budyko, M. I., 1956: Heat balance of the earth's surface. U.S. Weather Bureau, Washington, DC.

Charney, J., W. Quirk, S. Chow, and J. Kornfield, 1977: A comparative study of the effects of albedo change on drought in semiarid regions. J. Atmos. Sci., 34, 1366-1385.

Dickinson, R. E., 1984: Modeling evapotranspiration for three dimensional global climate models; climate processes and climate sensitivity. Geophys. Monogr., 29, Maurice Ewing Volume 5, Amer. Geophys. Union, Washington, DC, 58-72.

- - A. Henderson-Sellers, P. J. Kennedy, and M. F. Wilson, 1986: Biosphere-atmosphere transfer scheme (BATS) for the NCAR community climate model. NCAR Technical Note, $69 \mathrm{pp}$.

Entekhabi, D., and P. S. Eagleson, 1989: Land surface hydrology parameterization for atmospheric general circulation models including subgrid scale spatial variability. J. Climate, 2, 816-831.

Famiglietti, J., and E. F. Wood, $1991 \mathrm{a}$ : Evapotranspiration and runoff from large land areas: Land surface hydrology for atmospheric general circulation models. Land Surface-Atmospheric Interactions for Climate Models: Observations, Models, and Analyses, Eric F. Wood, Ed., Kluwer, 179-204.

$\longrightarrow$, and - $199 \mathrm{lb}$ : Comparison of passive microwave and modelderived estimates for soil moisture fields. Proc. Fifth International Colloquim-Physical Measurements and Signatures in Remote Sensing, Courchevel, France, European Space Agency, 321-326.

_- E. F. Wood, M. Sivapalan, and D. J. Thongs, 1992: A catchment scale water balance model for FIFE. J. Geophys. Res., 97(D17), $18997-19007$.

Hall, F. G., K. F. Huemmrich, S. J. Goetz, P. J. Sellers, J. E. Nickeson, 1992: Satellite Remote Sensing of Surface Energy Balance: Success, Failures and Unresolved Issues in FIFE. J. Geophys. Res., in press.

Holwill, C. J., and J. B. Stewart, 1992: Spatial variability of evaporation derived from aircraft and groundbased data. J. Geophys. Res., 97(D17), 18 673-18680.

Markham, B. L., and J. L. Barker, 1986: Landsat MSS \& TM postcalibration dynamic ranges, exoatmospheric reflectones and at satellite temperatures. EOSAT Landsat Tech. Note, 1, 3-8.

Rowntree, P. R., and J. R. Bolton, 1983: Simulation of the atmospheric response to soil moisture anomalies over Europe. Quart. J. Roy. Meteor. Soc., 109, 501-526.

Sato, N., P. J. Sellers, D. A. Randall, E. K. Schneider, J. Shukla, J. L. Kinter III, Y-T Hou, and E. Albertazzi, 1989: Effects of implementing the simple biosphere model in a general circulation model. J. Atmos. Sci., 46, 2757-2782.

Sellers, P. J., and J. L. Dorman, 1987: Testing the simple biosphere model ( $\mathrm{SiB}$ ) using point micrometereological and biophysical data. J. Climate Appl. Meteor., 26, 622-651.

- - Y. Mintz, Y. C. Sud, and A. Dalcher, 1986: A simple biosphere model $(\mathrm{SiB})$ for use within general circulation models. J. Atmos. Sci., 43, 1986.

- , F. G. Hall, G. Asrar, D. E. Strebel, and R. E. Murphy, 1988: The First ISLSCP Field Experiment (FIFE). Bull. Amer. Meteor. Soc., 69, 22-27.

- - W. J. Shuttleworth, J. L. Dorman, A. Dalcher, and J. M. Roberts, 1989: Calibrating the simple biosphere model for amazonian tropical forest using field and remote sensing data. Part I: Average calibration with field data. J. Appl. Meteor., 28, 727-759.

Shukla, J., and Y. Mintz, 1982: The influence of land-surface evapotranspiration on earth's climate. Science, 215, 1498-1501.

- C. Nobre, and P. J. Sellers, 1990: Amazon deforestation and climate change. Science, 247, 1322-1325.

Sivapalan, M., K. J. Beven, and E. F. Wood, 1987: On hydrological similarity. II: A scaled model of storm runoff production. Water Resour. Res., 23, 2266-2278.

Smith, E. A., A. Y. Hsu, W. L. Crosson, R. T. Field, L. J. Fritschen, R. J. Gurney, E. T. Kanemasu, W. Kustas, D. Nie, W. J. Shuttleworth, J. B. Stewart, S. B. Verma, H. Weaver, and M. Wesley, 1992: Area averaged fluxes and their time-space variability over the FIFE Experimental Domain. J. Geophys. Res., 97(D17), $18599-18622$

Sud, Y. C., P. Sellers, M. D. Chow, G. W. Walker, and W. E. Smith, 1990: Influence of biosphere on the global circulation and hydrologic cycle-A GCM simulation experiment. Agric. For. Meteor., 52, 133-188.

Walker, J. M., and P. R. Rowntree, 1977: The effect of soil moisture on circulation and rainfall in a tropical model. Quart. J. Roy. Meteor. Soc., 103, 29-46.

Wood, E. F., 1991: Global scale hydrology: Advances in land surface modeling. Rev. Geophys., Suppl., 29, 193-201.

- M. Sivapalan, K. J. Beven, and L. Band, 1988: Effects of spatial variability and scale with implications to hydrologic modeling. J. Hydrol., 102, 29-47.

,,---1990 : Similarity and scale in catchment storm response. Rev. Geophys., 28, 1-18. 